\title{
Learning Tastes Through Social Interaction
}

\author{
By
}

Alice Hsiaw

August 2014

\section{COLLEGE OF THE HOLY CROSS, DEPARTMENT OF ECONOMICS \\ FACULTY RESEARCH SERIES, PAPER NO. 14-05*}

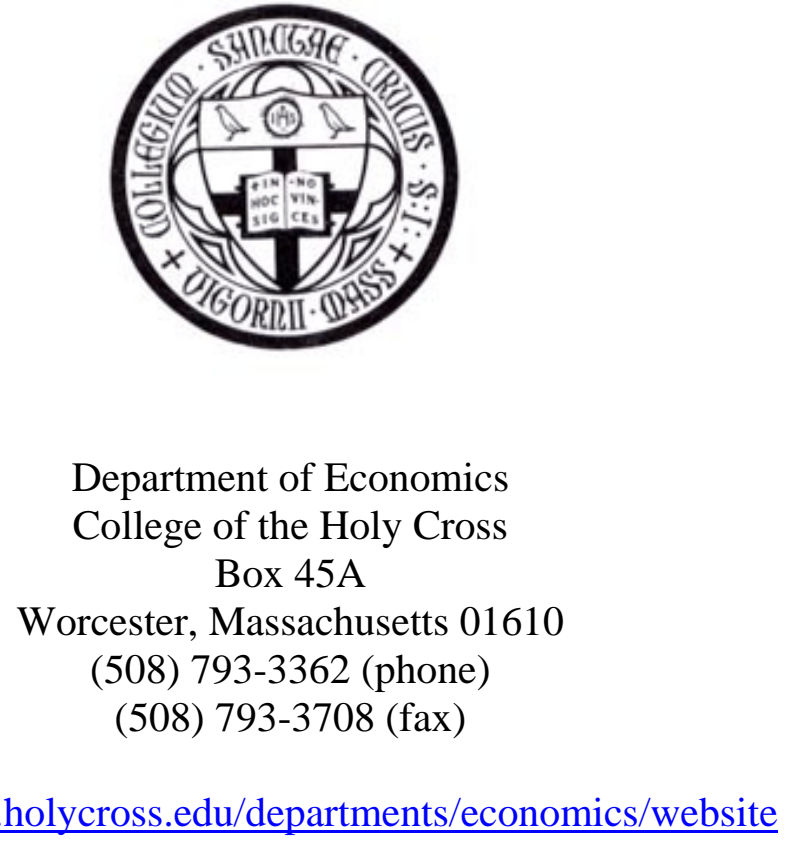

*All papers in the Holy Cross Working Paper Series should be considered draft versions subject to future revision. Comments and suggestions are welcome. 


\title{
Learning Tastes Through Social Interaction
}

\author{
By \\ Alice $\mathrm{Hsiaw}^{\dagger}$ \\ College of the Holy Cross
}

August 2014

\begin{abstract}
This paper offers an information-based model of social interaction, and analyzes optimal investment and pricing of services that facilitate interaction in a duopoly. Agents have uncertainty over their preferences but are aware that they are correlated with others', so there exists an incentive to communicate with others in the population. When a firm's good can be bundled with a coordination mechanism for its consumers, its value is endogenously determined due to a consumption externality. Although this mechanism increases total surplus, it is underprovided and consumer surplus decreases.
\end{abstract}

Acknowledgements: I thank my adviser, Roland B'enabou, for guidance and encouragement. I also thank Stephen Morris, Wolfgang Pesendorfer, Alisdair McKay, Dustin Tingley, seminar participants at the Princeton University Microeconomic Student Workshop, Dominique Lauga, and an anonymous referee for helpful comments. All remaining errors are my own.

\section{JEL Classification Codes:}

\section{Keywords:}

${ }^{\dagger}$ Alice Hsiaw, Department of Economics and Accounting, College of the Holy Cross, 1 College Street, Worcester, MA 01610; Phone: (508) 793-2687; Email: ahsiaw@holycross.edu 


\section{Introduction}

Engaging in social interaction through coordinated activities is a ubiquitous activity in modern society. Individuals have long met physically through clubs and community groups, and more recently can meet virtually through social networking sites. This paper studies consumers' demand for social interaction in the presence of a learning incentive, and firms' strategic investment and pricing choices when they have an opportunity to provide services that facilitate their consumers' interaction. I propose a model in which agents wish to "meet" with similar types in order to obtain information. They each have imperfect information about certain dimensions of their own tastes, but are aware that their preferences are correlated with others' in the population. I assume that agents can only communicate with those who have chosen common actions, a constraint that may be technological or physical, since doing so facilitates information exchange by enabling easier identification of like-minded individuals. ${ }^{1}$ For example, those at a bar or club can only communicate with others who are present, while membership is a prerequisite for communication on social networking sites and internet forums. In equilibrium, agents infer that others are more likely to be similar to themselves if they share common actions. Thus, the desire to "meet" and learn from others results in an endogenous value of matching and the formation of reference groups through coordinated actions.

The following example illustrates the model's intuitions. Suppose two Bostonians have preferences over bars in three different cities: Boston, Chicago, and New York. For each city, its set of bars is represented by a separate Salop (1979) circle whose twelve bars are located at each of the hour markings on a clock dial, and numbered accordingly. Agent A knows his favorite bars in Boston and Chicago, but has never been to New York. Likewise, Agent B knows his favorites in Boston and New York, but has never been to Chicago. Agent A's favorite Boston bar is the relatively obscure bar 8, but he decides to patronize the more popular bar 7 to increase his likelihood of meeting someone who has been to Chicago. There, A learns that B goes to New York's bar 7, from which he infers that the mapping between favorite Boston and New York bars is that the New York favorite is located at the same clock position as the Boston favorite. So A happily patronizes New York's bar 8 when he visits in the future. Likewise, learning where A goes in Chicago allows B to infer where he should go in Chicago when he visits. Thus, because they are aware that others' preferences are correlated with their own, they patronize the more popular bar 7 in Boston to increase the likelihood of meeting others and learning information.

\footnotetext{
${ }^{1}$ More generally, I could assume that agents can communicate more easily with those who chose common actions than those who did not. In this case, the qualitative results would be unchanged.
} 
Given the demand for coordination to expedite information exchange, firms have an obvious opportunity to supply some coordination service for their customers by increasing the recognizability of their consumption decisions. I assume that firms can invest in a "meeting" technology that is accessible only to their own customers and that facilitates their customers' "meeting" with one another and sharing information. Thus, this coordination service is bundled with the good or service itself. I assume that this investment is an initial, one-period fixed cost that has no effect on the future marginal costs of production, like setting up the technology's physical or virtual infrastructure. For example, a bar can organize events like trivia nights, or provide infrastructure like pool tables, to facilitate interaction among its patrons. Wine retailer WineStyles creates clubs and organizes events for its customers to meet in person, while Harley Davidson organizes events and operates a members-only Internet forum for Harley owners. I analyze equilibrium investment in a duopoly and, surprisingly, find that although total welfare increases, all consumers are worse off when the meeting technology exists than when it does not. In contrast to previous findings of "max-min differentiation" under multi-dimensional product differentiation (Economides, 1993; Dos Santos Ferreira and Thisse, 1996), I also find that firms differentiate maximally in both vertical (i.e., technology strength) and horizontal attributes (i.e., product variety). Only one of the two firms chooses to invest in the service even if such investment is costless, yet both firms charge sufficiently high prices that consumers are actually worse off than if a coordination service could not exist. This result occurs due to the presence of a consumption externality that weakens the firms' incentives to increase demand. Moreover, the meeting technology is underprovided relative to the social optimum.

The paper is organized as follows. Section 2 links this paper to related research. Section 3 describes the basic model. Section 4 illustrates the demand for coordination by solving for a pooling equilibrium, where agents choose identical actions that may diverge from their known tastes in order to learn from one another. Section 5 extends the model to include supply of the information-sharing mechanism through duopoly investment in a meeting technology. Section 6 concludes. Proofs are gathered in the Appendix.

\section{Literature Review}

This paper connects several lines of research. First, it relates to the bodies of work on consumption in social contexts and peer effects, and on word-of-mouth and social networks. It also contributes to the work on multi-dimensional product differentiation.

Much attention has been devoted to consumption in social contexts. In marketing, Muñiz and O'Guinn $(2001 ; 2005)$ discuss the role of brands as a channel for community formation 
because they serve as visual identification of others with similar tastes or beliefs. Kuksov (2007) considers the value of brands as a signaling device when agents engage in costly search for partnerships. In economics, consumption has been interpreted as a form of status signaling when identity is known and social preferences are a primitive of the model (Pesendorfer, 1995; Bagwell and Bernheim, 1996; Corneo and Jeanne, 1997, 1999). Though factors such as status may also play an important role, I propose an alternative motivation for the existence of coordinated consumption that endogenizes the costs and benefits of matching with others due entirely to a learning incentive.

This paper is also closely tied to the literature on peer effects as a source of consumption externalities. Peer effects on consumption can arise by entering preferences directly (Bernheim, 1994; Austen-Smith and Fryer, 2005), through imperfect information and social learning (Banerjee and Besley, 1990; Battaglini et al., 2005), or from technological innovations like recommender systems (Bergemann and Ozmen, 2004; Kuksov and Xie, 2010). Here, I contribute to the limited literature on firms' response to consumption externalities due to consumer communication by considering how a meeting technology enables individuals with imperfect self-knowledge to observe and learn from others.

This paper relates to the study of word-of-mouth and social networks by studying endogenous reference group formation to expedite communication about tastes. The word-ofmouth literature has primarily examined the role of sequential social learning in the creation of herding and information cascades (Bikhchandani et al., 1998). One line of research studies the effect of communication structure on information aggregation and efficiency when agents are boundedly rational (Ellison and Fudenberg, 1995; Bala and Goyal, 1998, 2001). Another analyzes firms' decisions and consumer welfare when fully rational consumers can communicate about the quality of goods through word of mouth (Vettas, 1997; Alcalá et al., 2006; Navarro, 2006). While the aforementioned work has considered the effects of given social structures, social network theory studies networks' stability and efficiency when link formation is endogenous (Jackson and Wolinsky, 1996; Galeotti et al., 2006).

The question of how firms choose to differentiate products in spatial competition has been studied extensively. In uni-dimensional settings, firms maximally differentiate in horizontal (d'Aspremont et al., 1979; Kats, 1995) or vertical (Shaked and Sutton, 1982) competition, because the incentive to relax price competition through differentiation dominates the incentive to increase demand through similarity. Studies of multi-dimensional differentiation with both horizontal and vertical attributes have found that firms engage in "max-min differentiation" (Economides, 1993; Dos Santos Ferreira and Thisse, 1996), differentiating maximally in one dimension and minimally in the other, because they can simultaneously exploit weakened price competition and increase demand. Laffont et al. (1997) find that competition 
can intensify when monotonic network externalities exist between horizontally differentiated goods. In this paper, firms engage in both vertical differentiation through social network strength and horizontal differentiation through location choice. In contrast to previous findings, firms differentiate maximally in both dimensions because the presence of a consumption externality weakens the demand effect.

\section{The Model}

Let the agents in a continuum population choose a vector of actions $\mathbf{x}$ from a set $\mathbf{X}$. For simplicity, I assume that this vector has only three components, $\mathbf{x}=\left(x_{1}, x_{2}, x_{3}\right)$, where the full action set is the Cartesian product of three action spaces, $\mathbf{X}=X_{1} \times X_{2} \times X_{3}$. In accordance with Salop's (1979) circular model of horizontal differentiation, the set of actions in each action space is $X_{j}=\left\{S^{1} \cup \emptyset\right\}$ for $j=1,2,3$, where numerical actions lie on a circle with unit circumference $\left(S^{1}=\left\{x \in \mathbb{R}^{2}:\|x\|=\frac{1}{2 \pi}\right\}\right)$ and the empty set denotes the action of not choosing a number. Each of these action spaces can be interpreted quite broadly, where there exists no vertical differentiation within them. For example, agents can choose a bar to patronize (or not) in each of three different cities.

An agent $i$ receives baseline utility $v_{j}^{i}$ from choosing any action $x_{j}^{i} \in S^{1}$, and utility 0 if $x_{j}=\emptyset$. I assume that this utility is the same across individuals, $v_{j}^{i}=v_{j} \forall i$. Each agent has an ideal variety over each of these sets $X_{j}, j=1,2,3$, so he can be described by a vector of tastes $\boldsymbol{\theta}^{\boldsymbol{i}}=\left(\theta_{1}^{i}, \theta_{2}^{i}, \theta_{3}^{i}\right)$, which denotes his type, where $\theta_{j}^{i} \in S^{1} \forall i, j$. The full type space $\Theta$ is the Cartesian product of the taste spaces, $\Theta=\Theta_{1} \times \Theta_{2} \times \Theta_{3}$, where $\Theta_{j}=S^{1}$ for all $j=1,2,3$, so no agent's ideal is to refrain from an activity. An agent incurs disutility from choosing a numerical action that differs from his ideal, where the disutility is, without loss of generality, a quadratic function of the distance from his ideal taste. To guarantee that agents never abstain from an activity entirely, let $v_{j} \geq \frac{1}{4} \forall j$.

Assumption 1 An agent's utility is additively separable across action spaces and decreases quadratically in the distance between his action and his taste in each action space: $U_{i}\left(x_{1}^{i}, x_{2}^{i}, x_{3}^{i}\right)=$ $\sum_{j=1}^{3}\left[v_{j}-d\left(\theta_{j}^{i}, x_{j}^{i}\right)^{2}\right]$, where $d\left(\theta_{j}^{i}, x_{j}^{i}\right)$ is the distance between $\theta_{j}^{i}$ and $x_{j}^{i}$ on the unit circle when $x_{j}^{i} \neq \emptyset$.

There are two periods in which an agent $i$ takes actions in $X$, but each agent only has unit demand in each action space over the two period span. For a given $j$, if he chooses $x_{j}^{i} \in S^{1}$ in the first period, then he must choose $x_{j}^{i}=\emptyset$ in the second period. If he chooses

$x_{j}^{i}=\emptyset$ in the first period, then he can choose $x_{j}^{i} \in\left\{S^{1} \cup \emptyset\right\}$ in the second period. For simplicity, I assume that the agent does not discount the future $(\delta=1)$. 
Assumption 2 Imperfect information: Each agent knows only two components of his type, and his information set is drawn from $\left\{\left(\theta_{1}, \theta_{2}\right),\left(\theta_{1}, \theta_{3}\right)\right\}$. Each of these information types is equally likely.

Furthermore, I assume that agents have imperfect information about their types. Specifically, each agent only knows two components of his type. Clearly, there is no reason that all agents should know their tastes in $\Theta_{1}$ rather than $\Theta_{2}$ or $\Theta_{3}$. The general point is that there must exist at least one taste space, and corresponding action space, in which agents who have mutually beneficial information can identify one another through their choices. ${ }^{2}$ Beyond having a common taste space over actions that can coincide, each agent must have information about another taste space that the other does not, so that communication is mutually desirable. Thus, a minimum of three taste spaces, with corresponding action spaces, is required for differing information types to take actions to foster communication with others. ${ }^{3}$

Assumption 3 Partial information about an agent's type is uninformative: $E\left(\theta_{3}^{i} \mid \theta_{1}^{i}, \theta_{2}^{i}\right)=$ $E\left(\theta_{3}^{i}\right)$ and $E\left(\theta_{2}^{i} \mid \theta_{1}^{i}, \theta_{3}^{i}\right)=E\left(\theta_{2}^{i}\right)$.

When an agent faces uncertainty about one of his tastes, he has a clear incentive to improve his information regarding that taste. For simplicity and without loss of generality, I assume that an information type's information set is completely uninformative about the third, unknown taste. As his information set becomes more informative, his incentive to seek information from others weakens, but is nonetheless present, so his problem is qualitatively identical. Clearly, the agent will only have no incentive to learn from others if he is able to fully infer his third taste from his own information set. In particular, let $E\left(d\left(\theta_{j}^{i}, \theta_{k}^{i}\right)\right)=\frac{1}{4} \forall i$, where $j \neq k$ and $d\left(\theta_{j}^{i}, \theta_{k}^{i}\right)$ denotes the distance between $\theta_{j}^{i}$ and $\theta_{k}^{i}$ on the unit circle. That is, in the absence of any new information, the agent has a uniform prior about the relationship between any two tastes. Moreover, given an agent's information type $\left(\theta_{1}^{i}, \theta_{j}^{i}\right)$, I assume that $P\left(d\left(\theta_{1}^{i}, \theta_{k}^{i}\right)=0 \mid \theta_{1}^{i}, \theta_{j}^{i}\right)=P\left(d\left(\theta_{1}^{i}, \theta_{k}^{i}\right)=\frac{1}{2} \mid \theta_{1}^{i}, \theta_{j}^{i}\right)=\frac{1}{2}$, where $\theta_{k}^{i}$ is $i$ 's unknown taste. This is equivalent to supposing that $P\left(d\left(\theta_{1}^{i}, \theta_{k}^{i}\right)=a \mid \theta_{1}^{i}, \theta_{j}^{i}\right)=P\left(d\left(\theta_{1}^{i}, \theta_{k}^{i}\right)=\frac{1}{2}-a \mid \theta_{1}^{i}, \theta_{j}^{i}\right)=\frac{1}{2}$, where $a \in\left[0, \frac{1}{2}\right]$.

Assumption 4 Agents' preferences are perfectly correlated with those of others in the population: $\left(d\left(\theta_{1}^{i}, \theta_{2}^{i}\right), d\left(\theta_{1}^{i}, \theta_{3}^{i}\right)\right)=\left(d\left(\theta_{1}^{m}, \theta_{2}^{m}\right), d\left(\theta_{1}^{m}, \theta_{3}^{m}\right)\right)$ for all agents $i \neq m$.

\footnotetext{
${ }^{2}$ Alternatively, we could suppose that there are three information types, drawn from the set $\left\{\left(\theta_{1}, \theta_{2}\right),\left(\theta_{1}, \theta_{3}\right),\left(\theta_{2}, \theta_{3}\right)\right\}$. This specification leads to the same qualitative results when we have the perfect correlation structure stated below, but is technically incompatible with imperfect correlation.

${ }^{3}$ We can imagine a very different scenario, in which agents are perfectly informed about their tastes in $\Theta_{1}$ and each receive noisy information about their tastes in $\Theta_{2}$. While this generates a learning incentive to communicate for both parties, it is akin to a setting in which agents simply wish to share private information about a good's objective quality. In this case, the need to coordinate with those with similar tastes based on observed actions and experiences on multiple dimensions is absent.
} 
Agents are aware that their (multi-dimensional) preferences are perfectly correlated with those of others in the population but are unaware of its sign. For example, the mapping between favorite bars in Boston and New York is identical across agents. Though they may well have different Boston favorites, both Agent A and B's New York favorites are located at the same clock position relative to their respective Boston favorites. After Nature determines the realized state of relationships $\left(d\left(\theta_{1}, \theta_{2}\right), d\left(\theta_{1}, \theta_{3}\right)\right)$, the agents receive their information sets. In the absence of correlated preferences across members of the population, there would be no learning incentive to communicate with others. The assumption of perfect correlation is made for simplicity and without loss of generality. As long as correlation is not zero, we can obtain the same qualitative results. As expected, decreasing the degree of correlation is equivalent to increasing the noisiness of information or decreasing the ease of communication (Appendix A.1).

Assumption 5 The distribution of agents' tastes is uniform in each taste space $\Theta_{j}$, where $j=1,2,3$.

Because the agents' incentives to pool on an action are clearly influenced by the underlying distribution of the population, I assume uniformity to ensure that such an equilibrium is not driven trivially by the nature of the distribution. The same motivation underlies the assumption that each information type is equally likely to occur in the population.

If agent $i$ chooses an $x_{j}^{i} \neq \emptyset$ in period 1 , then he might receive useful information about the behavior of others in the population, which can inform him about his own preferences along other dimensions. Figure 1 depicts the information mechanism for any action $x_{j} \neq$ $\emptyset$. Let $\mu_{j}\left(x_{j}\right)$ be the proportion of individuals who have chosen $x_{j}$ in period 1 , and let $\eta_{j}\left(x_{j}\right)=\min \left\{\alpha \mu_{j}\left(x_{j}\right), 1\right\}$, where $\alpha \geq 0$ is a constant. The parameter $\alpha$ measures the ease of communication among those who have chosen a common action. The agent is more likely to encounter others who chose the same action $x_{j}$ if their numbers in the population are relatively large, so we can interpret this probability as the result of search success. Specifically, he meets another agent $m$ who has chosen the same action $x_{j}$ with probability $\eta_{j} .{ }^{4}$ However, he is unsuccessful in meeting another agent with probability $1-\eta_{j}$. In this case, choosing action $x_{j}$ does not produce new information about his unknown tastes. Denoting the signal he receives from choosing action $x_{j}$ by $s_{j}\left(x_{j}\right)$, acquiring no information is equivalent to $s_{j}\left(x_{j}\right)=\emptyset$. Likewise, if agent $i$ chooses no action $\left(x_{j}^{i}=\emptyset\right)$ in period 1 , then he observes nothing, i.e. $s_{j}\left(x_{j}\right)=\emptyset$ with certainty. If he chooses action $x_{j}$ and does meet another agent

\footnotetext{
${ }^{4}$ Alós-Ferrer (1999) constructs a uniform matching scheme that depends on type functions to enable the application of the "law of large numbers" to random matching schemes, to address a well-known "measurability problem" that can arise (Judd, 1985; Feldman and Gilles, 1985).
} 
$m$, then agent $i$ learns $m$ 's first-period actions $\left(s_{j}\left(x_{j}\right)=\mathbf{x}^{m}\right)$. While information about tastes is fully revealing, actions are less informative since they can deviate from ideal tastes.

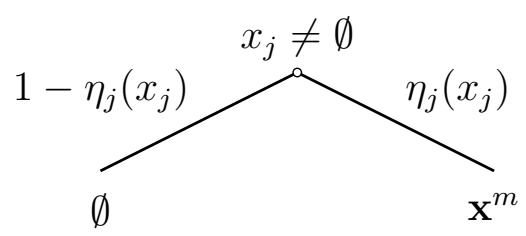

Figure 1: The Information Mechanism

The model separates two parts of the information acquisition process - the probability of meeting another and the value of information conditional upon meeting. The probability of finding information increases with the proportion of others who chose the same action. Due to the correlation structure of preferences, the value of information decreases if this proportion becomes too large. In the most extreme case, an agent obtains no information if all agents of the same information type choose the same action, since he is aware that $\mathbf{x}^{m}$ is equally likely to have been chosen by any preference types in $\Theta_{1}$. Thus, the incentive to coordinate on a common action derives from its ability to expedite communication, and its value to any agent who does so is endogenously determined by equilibrium behavior and may be non-monotonic. ${ }^{5}$

Sharing information about tastes is sometimes possible, but not easy. Although I have assumed the constraint, whether technological or physical, that agents can only communicate with others who share a common action, I could more generally assume that agents can communicate more easily with those who chose common actions than those who did not. Since it is the relative benefit of coordination that is relevant to an agent's action decision, increasing the ease of communication among agents who did not choose common actions is qualitatively equivalent to decreasing $\alpha$ in the current model. If agents can communicate freely (and honestly) about their tastes with anybody, regardless of their actions, then there is no additional informational benefit to action coordination, which is equivalent to the standard case of $\alpha=0$.

Figure 2 describes the series of events.

\footnotetext{
${ }^{5}$ In contrast, Corneo and Jeanne (1999) assume that agents wish to coordinate on actions associated with high-status types due to assumed positive status externalities from doing so, but communication itself occurs entirely separately from coordination. Here, communication due to a learning motivation is the sole impetus for coordination of any degree.
} 


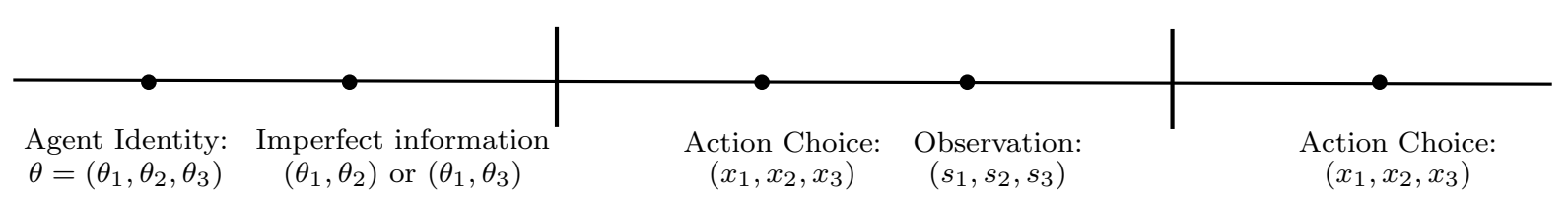

Figure 2: Timeline of Events

\section{Equilibria}

To illustrate the demand for coordination, I solve for and characterize pooling equilibria, in which groups of agents choose identical actions that may diverge from their known tastes in order to learn from one another. In such equilibria, I show that this learning incentive generates an endogenous value of matching and the formation of reference groups with similar tastes through conformity. This desire for coordination will present an opportunity for firms to supply such an information mechanism through their products, which can serve as natural coordinating devices.

To learn more about his unknown $\theta_{k}$, an agent might postpone his action $x_{k}$ and choose an $x_{j} \neq \theta_{j}$ in period 1 that coordinates with others. No agent pools in the second period, since there is no information gain from doing so. Hence, I look for pooling in a "symmetricby-types" equilibrium in the first period in the following sense: The $\left(\theta_{1}, \theta_{2}\right)$ and $\left(\theta_{1}, \theta_{3}\right)$ information types pool on the $X_{1}$ action space by acting symmetrically. These two types clearly will not pool in either the $X_{2}$ or $X_{3}$ spaces, respectively, since there would be no information gain from doing so. In fact, I show that any equilibrium must be "symmetricby-types" (Appendix A.3). Since $\left(\theta_{1}, \theta_{2}\right)$ and $\left(\theta_{1}, \theta_{3}\right)$ types act symmetrically, I solve the $\left(\theta_{1}, \theta_{2}\right)$ information type's maximization problem. Moreover, pools can be classified through symmetry or asymmetry in the compositions of members' tastes within a given dimension. A pool at the point $x_{1}$ is symmetric if $d\left(\underline{\theta}_{1}, x_{1}\right)=d\left(\bar{\theta}_{1}, x_{1}\right)$, where $\underline{\theta}_{1}$ and $\bar{\theta}_{1}$ are the marginal agents at the pool's endpoints, and asymmetric otherwise. The range of asymmetric equilibria that can occur is far less restricted, but they do not occur in equilibrium in the ensuing application to firm investment in meeting technology, so I do not characterize them.

To characterize the full set of symmetric, "symmetric-by-types" equilibria, I begin with the case in which an agent's best alternative to pooling at a given point $x_{1}$ is not to pool, which establishes an upper bound on individual pool size. I then consider the complete set of pools in an action space, where the characterization of the case in which an agent's best alternative to pooling at $x_{1}$ is some other point $x_{1}^{\prime}$ follows from this derivation.

If agent $i$ 's best option is not to pool, then he acquires no additional information about 
$\theta_{3}$ and chooses $\left(x_{1}=\theta_{1}, x_{2}=\theta_{2}\right)$ as well as $x_{3}$ in period 1 . Because $P\left(d\left(\theta_{1}, \theta_{k}\right)=0 \mid \theta_{1}, \theta_{j}\right)=$ $P\left(d\left(\theta_{1}, \theta_{k}\right)=\frac{1}{2} \mid \theta_{1}, \theta_{j}\right)=\frac{1}{2}$, choosing the optimal $x_{3}$ is equivalent to choosing the optimal distance from $\theta_{1}$, where $t_{3}=d\left(\theta_{1}, x_{3}\right)$ and the agent's problem is:

$$
\max _{t_{3}}-\frac{1}{2}\left(t_{3}\right)^{2}-\frac{1}{2}\left(\frac{1}{2}-t_{3}\right)^{2}
$$

for which the solution is $t_{3}=\frac{1}{4}$ and his expected payoff is $v_{1}+v_{2}+v_{3}-\left(\frac{1}{4}\right)^{2}$. There are two solutions to $x_{3}$ such that $t_{3}=\frac{1}{4}$, but his expected payoff is identical in either case so the agent is indifferent between the two actions.

If the agent pools at $x_{1}$, he observes the actions of another agent with probability $\eta_{1}\left(x_{1}\right)$. The correlation structure implies that $i$ can perfectly infer $\theta_{k}^{i}$ given any $\mathbf{x}^{m}$ when up to half of the population of information types pools monotonically at $x_{j}$. When the pool exceeds this size, $i$ knows that signal dilution arises from the presence of those whose tastes diverge too much from the rest of the pool. For example, Agent A patronizes bar 7 to learn the mapping of whether his favorite New York bar is at the same clock position as his Boston favorite or 180 degrees from it. When at most those with Boston favorites 4-9 (i.e., up to half the population) go to bar 7, then the information sets from each state of the world are disjoint so the true state will be revealed by any $m$ that A meets there. Otherwise, A's evaluation of the benefit of patronizing bar 7 accounts for the fact that they are not disjoint. ${ }^{6}$

Suppose that $\mu_{1}\left(x_{1}\right) \leq \frac{1}{2}$, so that any $\mathbf{x}^{m}$ from a different information type is fully informative. Then $m$ is equally like to be a $\left(\theta_{1}, \theta_{3}\right)$ or $\left(\theta_{1}, \theta_{2}\right)$ type, so $i$ learns his $\theta_{3}$ perfectly with probability $\frac{\eta_{1}}{2}$, and learns nothing with probability $1-\frac{\eta_{1}}{2}$. His expected payoff from pooling at $x_{1}$ is $v_{1}-\left[d\left(\theta_{1}, x_{1}\right)\right]^{2}+v_{2}+\left[v_{3}-\left(1-\frac{\eta_{1}}{2}\right)\left(\frac{1}{4}\right)^{2}\right]$. If pooling is optimal, the net expected information gain from pooling at $x_{1}$ must exceed the loss from choosing an action that differs from one's own ideal, $\theta_{1}$ :

$$
\left(\frac{\eta_{1}}{2}\right)\left(\frac{1}{4}\right)^{2} \geq d\left(\theta_{1}, x_{1}\right)^{2} .
$$

Let $\alpha$ be sufficiently low that $\alpha \mu_{1} \leq 1 .^{7}$ Using Equation (1), the maximal equilibrium pool size is derived from the indifference conditions for a given $x_{1} \in S^{1}$ since the marginal types are indifferent between pooling at $x_{1}$ and not pooling anywhere. Let $\bar{\theta}_{1}\left(x_{1}\right)$ be the highest

\footnotetext{
${ }^{6}$ For example, if all those with Boston favorites 3-10 go to bar 7, then A might meet an $m$ who goes to New York bar 3. Based on this information, A cannot determine the true mapping because this $m$ is equally likely to be someone whose Boston favorite is bar 3 or 9 . But if A meets an $m$ who goes to New York bar 6 , he can infer that his New York favorite must be at the same clock position as his Boston favorite.

${ }^{7}$ For now, I fix this exogenous parameter to work directly with $\alpha \mu_{j}\left(x_{j}\right)$ without worrying about a nonlinear probability function, since I assume $\mu_{1}\left(x_{1}\right) \leq \frac{1}{2}$ in this equilibrium. When $\alpha$ is an endogenous variable in the duopoly application, this assumption will no longer be necessary, since it is suboptimal to choose a costly $\alpha$ such that $\alpha \mu_{1}>1$.
} 


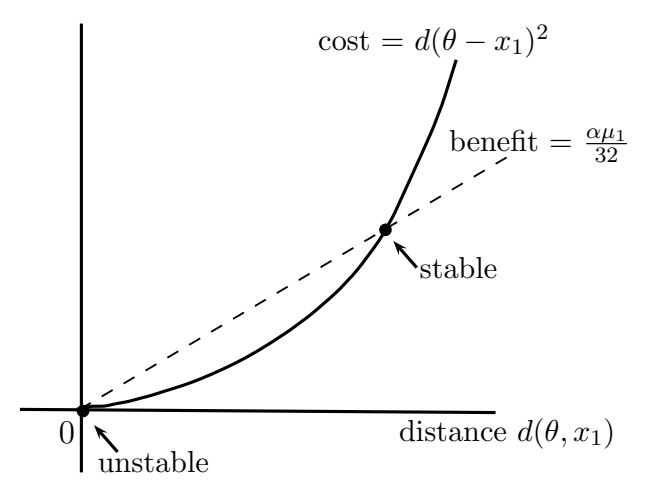

Figure 3: Symmetric Equilibria

type in the pool and $\underline{\theta}_{1}\left(x_{1}\right)$ be the lowest type in the pool, so $\mu_{1}\left(x_{1}\right)=d\left(\bar{\theta}_{1}\left(x_{1}\right), \underline{\theta}_{1}\left(x_{1}\right)\right)$. Then an interior solution with $\mu_{1}\left(x_{1}\right) \leq \frac{1}{2}$ requires:

$$
\begin{aligned}
& \frac{\alpha \mu_{1}}{2}\left(\frac{1}{16}\right)=d\left(\bar{\theta}_{1}, x_{1}\right)^{2} \\
& \frac{\alpha \mu_{1}}{2}\left(\frac{1}{16}\right)=d\left(\underline{\theta}_{1}, x_{1}\right)^{2},
\end{aligned}
$$

where $x_{1} \in\left[\underline{\theta}_{1}, \bar{\theta}_{1}\right]$. Unsurprisingly, the coordinated action $x_{1}$ is undetermined so there is a multiplicity of equilibria. For any given $x_{1}$, there are two solutions for the system of endpoints $\bar{\theta}_{1}$ and $\underline{\theta}_{1}$. The first is the pooling equilibrium such that

$$
d\left(\underline{\theta}_{1}, x_{1}\right)=d\left(\bar{\theta}_{1}, x_{1}\right)=\frac{\alpha}{16}
$$

and consequently $\mu_{1}\left(x_{1}\right)=\frac{\alpha}{8}$. Since $\alpha \mu_{1} \leq 1$, then $\mu_{1}\left(x_{1}\right)<\frac{1}{2}$ in equilibrium, as surmised. The second is the separating equilibrium in which $x_{1}=\bar{\theta}_{1}=\underline{\theta}_{1}$, but only the pooling equilibrium is stable (Appendix A.2). Figure 3 illustrates the symmetric pooling equilibria characterized by Equations (2) and (3), because the marginal agents' problems are symmetric about the pooling point. Since the best alternative is not to pool, $\mu_{1}\left(x_{1}\right)=\frac{\alpha}{8}$ is the unique upper bound on the size of any individual pool in equilibrium.

Having constructed the maximal individual pool, I now consider the complete set of pools in an action space. The fact that only the pooling equilibrium is stable implies that all agents in the $\Theta_{1}$ taste space will pool somewhere on the action space $X_{1}$. Since all agents in a given pool derive the same information benefit but travel costs increase in distance from the pooling point, no pool can be a disjoint interval or overlap with another. If every pool is exactly of size $\frac{\alpha}{8}$, this presents an $n$-integer problem if the parameter $\alpha$ is a value such that 
the number of pools required to "fill" the space completely is not an integer. However, for pool sizes below the upper bound, marginal agents' best alternative to pooling at a point $x_{1}$ is to pool at a some other point $x_{1}^{\prime}$, rather than not to pool anywhere. Thus, smaller symmetric pools of size $\mu_{1} \in\left(0, \frac{\alpha}{8}\right]$ can stably exist and satisfy the $n$-integer condition. This implies that any pool is endogenously composed only of sufficiently similar types, so the learning incentive remains strong even for marginal agents. All agents who choose a common action infer that they have similar tastes and benefit from sharing information with one another. Hence, peers exhibit conformity of behavior in order to identify one another and form reference groups to learn their tastes.

Clearly, Equation (1) implies that any configuration in which the $X_{1}$ space is completely filled with pools of identical size, where $\mu_{1} \in\left(0, \frac{\alpha}{8}\right]$ and the value of $\alpha$ allows for the number of pools to be an integer, is a stable equilibrium. Any marginal agent between two adjacent pooling points is indifferent between joining either, and is strictly better off joining a pool than not pooling anywhere if $\mu_{1}<\frac{\alpha}{8}$. Thus for any $\alpha>0$, there exists at least one equilibrium in which all pools are symmetric and identical in size. Furthermore, there also exist equilibria in which adjacent symmetric pools can be of different size, but are bounded by $\frac{\alpha}{8}$. In particular, at most two differing pool sizes can simultaneously exist in an action space, as a configuration in which adjacent pools alternate in size between $\mu_{1}\left(x_{1}\right)$ and $\mu_{1}\left(x_{1}^{\prime}\right)$ subject to $d\left(x_{1}, x_{1}^{\prime}\right)=\frac{\alpha}{16}$. Proposition 1 describes the complete set of symmetric pooling equilibria, where the complete proof is provided in Appendix A.3.

Proposition 1 1. For all $\alpha>0$, there exists a unique type of pooling equilibrium, which is characterized by the following behavior:

(a) No agent pools in more than one action space.

(b) In period 1, the two information types pool identically on an action $x_{1} \in X_{1}$ where $\theta_{1}$ is known and choose $x_{k}=\emptyset$ for unknown $\theta_{k}$.

(c) In any action space where an agent knows his taste and does not pool, he chooses his known ideal.

2. For any value of $\alpha$ such that $\alpha \mu\left(x_{1}\right) \leq 1$, there exists at least one equilibrium in which the action space $X_{1}$ is completely filled with symmetric pools. Furthermore, only two configurations are possible when all pools are symmetric:

(a) All pools are identical in size $\mu_{1}$, where $\mu_{1} \in\left(0, \frac{\alpha}{8}\right]$.

(b) Exactly two differing pool sizes, $\mu_{1}$ and $\mu_{1}^{\prime}$, coexist and alternate, where $\mu_{1} \in\left(0, \frac{\alpha}{8}\right)$ and $\mu_{1}^{\prime}=\frac{\alpha}{8}-\mu_{1}$. 
Unsurprisingly, pooling location in itself does not affect the size of a pool. As the ease of communication increases, agents are willing to take actions further from their ideal tastes to learn from others.

Proposition 2 In action space $X_{1}$, a symmetric pool $\mu_{1}\left(x_{1}\right)$ about the action $x_{1}$ exhibits the following properties:

1. Pool size $\mu_{1}\left(x_{1}\right)$ is invariant to location $x_{1}$.

2. Pool size increases with $\alpha$, attaining a maximum of $\frac{\alpha}{8}$.

Agents have an incentive to communicate with like-minded others when they have imperfect information about their own preferences but can potentially learn about them from others. I have shown that this incentive is sufficiently strong that despite the option to choose actions that perfectly coincide with their ideal tastes, they endogenously coordinate on actions that diverge from their ideal tastes and unambiguously benefit from communication with like-minded others. That is, coordination with others is preferred to its absence if it facilitates communication even when agents' actions are unconstrained, indicating an opportunity for firms to supply such an information mechanism through consumption of their products. The questions of interest are whether firms would prefer to provide such an information mechanism and how this decision affects pricing and welfare.

\section{Duopoly with Investment}

A natural extension of this framework is to consider consumption of a good as a form of action, so that an action space $X_{j}$ becomes the variety space of an "experience good" $j$, over which there is a uniform distribution of consumers with ideal varieties $\theta_{j}$. Books, clothing, automobiles, and bars are among typical experience goods for which consumers have ideal tastes, even holding objective quality constant. In the previous section, I have shown that when individuals have an incentive to learn from one another due to imperfect information about their own preferences, there is demand for coordination to successfully exchange information. In this context, firms can serve as the suppliers of the information mechanism that allows consumers to meet one another more easily, even if they can only offer goods in a single action space.

Suppose that one action space (i.e., $X_{1}$ ) is actually a good or service space in which agents must choose from the set of varieties that firms offer. This restriction reasonably reflects the limited availability of varieties for most goods in the real world. More specifically, I assume that there are only two varieties of the good available, each of which is offered by 
a different firm. All consumers have the same reservation price $v_{1}$ for the good, $v_{1}>0$. Because it is arguably more difficult for agents to coordinate on common actions when there is an infinite spectrum of possible actions, the limited variety of a consumption good can serve as a coordinating device for consumers to try to meet one another, an opportunity that firms offering these varieties can try to exploit.

Each of two firms offers a variety in $X_{1}$, denoted by $x_{11}$ and $x_{12}$ at prices $p_{1}$ and $p_{2}$, respectively. Firms simultaneously choose the locations of the varieties. Before setting prices, each firm $n$ can invest in a coordination service whose efficacy is measured by the parameter $\alpha_{n} \geq 0, n=1,2$, according to a quadratic cost function. This coordination service is a "meeting" or "recognition" technology, such as a physical club or an internet community. For example, the wine retailer WineStyles creates clubs and organizes events for customers to meet in person, while Harley Davidson operates an internet forum for owners and sells its own clothing line. A bar can organize events (e.g., sports night, trivia night) or provide infrastructure like pool tables to facilitate interaction among its patrons. ${ }^{8}$ The information mechanism for the meeting technology is as described in the basic model, where the parameter $\alpha$ measures its effectiveness. A firm's customers cannot "meet" or "recognize" each other and exchange information if the firm does not invest $\left(\alpha_{n}=0\right)$. The marginal cost of producing one unit of any variety is identical for both firms, denoted $c$ where $c \geq 0$, and is independent of the level of technology investment. This assumption is plausible in the preceding examples, and allows us to isolate the effect of investment. Firms cannot price discriminate.

Although such firms are only providing goods in a single action space, there exists a consumption externality that arises from the correlation of consumers' tastes across action spaces. Since consumers in this action space apply the information benefits from learning about others' preferences to other action spaces, the presence of a meeting technology will certainly affect behavior in this market. To isolate the externality's effect, I focus on the simplest setting, in which firms within a single action space can offer a coordinating device for consumers to learn, and cannot offer products in other action spaces. For brevity of exposition, I assume that the firms' varieties $x_{1 n}$ where $n=1,2$ are exogenously given and equidistant $\left(d\left(x_{11}, x_{12}\right)=\frac{1}{2}\right)$. Endogenizing location leads to equidistant location choices and therefore identical results (Appendix A.6).

\section{Timeline}

\footnotetext{
${ }^{8}$ Of course, some meeting technologies like trivia games or pool tables can also offer inherent consumption value to consumers. The addition of such utility does not affect qualitative results, so I abstract from it to focus on the information-sharing mechanism.
} 
1. Firms $n$ simultaneously choose varieties $x_{1 n}$ (i.e., location), where $x_{1 n} \in[0,1]$ for $n=1,2$.

2. Firms $n$ simultaneously choose technologies $\alpha_{n}$ and incur investment costs $c_{\alpha} \alpha_{n}^{2} \geq 0$ where $c_{\alpha} \geq 0$ and $n=1,2$.

3. Firms simultaneously choose prices $p_{n}, n=1,2$.

4. Observing $x_{1 n}, \alpha_{n}$ and $p_{n}$ where $n=1,2$, consumers choose whether or not to buy variety $x_{11}$ or $x_{12}$.

5. (Consumers choose to buy goods in other markets/dimensions.)

I proceed by solving the model backwards in pure strategies, considering each pair of strategies in turn. The market is covered whenever marginal cost $c$ is sufficiently low and the reservation price $v$ is sufficiently high. In Appendix A.6.6, I derive the exact size of $v-c$ required for existence of the equilibrium in which the market is covered. I also show that an equilibrium in which the market is not covered cannot exist whenever such a covered equilibrium exists. Because firms' locations are equidistant, consumers' behavior will be symmetric. Let $\mu_{n}$ denote firm $n$ 's market share. Without loss of generality, let $\alpha_{1} \geq \alpha_{2}$.

\subsection{Demand}

Suppose that the firm with a stronger meeting technology captures the majority of the market: $\alpha_{1} \geq \alpha_{2}$ and $\mu_{1} \geq \frac{1}{2}$. With probability $1-\frac{\eta_{1}}{2}$, a customer of firm 1 acquires no new information about his own tastes, because he either meets no one or another $\left(\theta_{1}, \theta_{2}\right)$ agent, from whom he learns nothing about $\theta_{3}$. In this case, he chooses an action such that $d\left(\theta_{1}, \theta_{3}\right)=\frac{1}{4}$ and his expected payoff from choosing an action in the $X_{3}$ space is $v_{3}-\left(\frac{1}{4}\right)^{2}$. With probability $\frac{\eta_{1}}{2}$, he meets an agent $m$ of type $\left(\theta_{1}, \theta_{3}\right)$ who chose $x_{11}$. If he observes $m$ 's actions $\left(\mathbf{x}^{m}\right)$, then he must account for the possibility that he encounters an $m$ whose tastes differ too much to yield useful information. When $\mu_{1} \geq \frac{1}{2}$, there is a proportion, $\frac{2\left(\mu_{1}-\frac{1}{2}\right)}{\mu_{1}}=2-\frac{1}{\mu_{1}}$, of $m$ 's from whom observing their actions yields no new information about the true state. Observing such an $m$ 's choice of $x_{3}$ is uninformative because it is equally likely that $d\left(\theta_{1}, x_{3}\right)=0$ or $d\left(\theta_{1}, x_{3}\right)=\frac{1}{2}$, as both types of consumers have chosen the same $x_{11}$. In this event, the agent faces the same problem as when he does not meet any other consumer, so his expected payoff from choosing an action in the $X_{3}$ space is $v_{3}-\left(\frac{1}{4}\right)^{2}$. However, there is also a proportion, $1-\left(2-\frac{1}{\mu_{1}}\right)=\frac{1}{\mu_{1}}-1$, of $m$ 's from whom observing their actions allows the consumer to perfectly infer his own taste. In this event, his expected payoff is $v_{3}$, since 


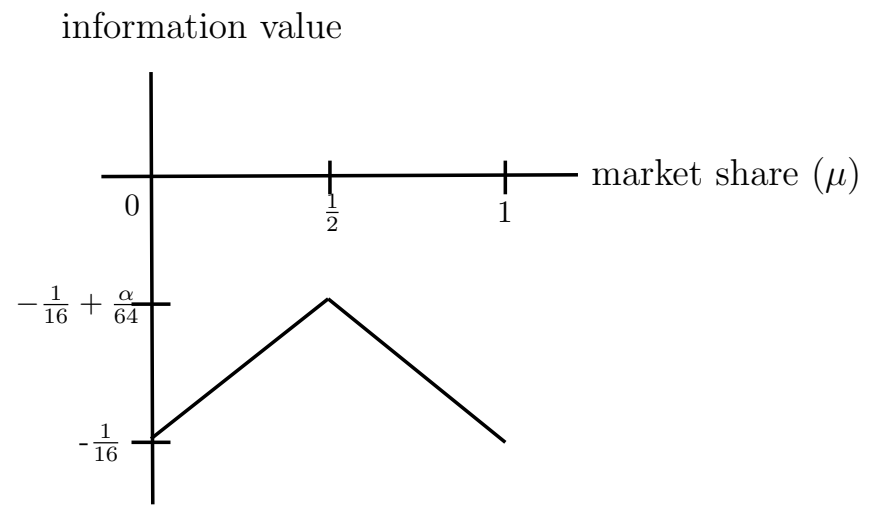

Figure 4: Expected Information Value

he can then select $x_{3}=\theta_{3}$ in the second period. Therefore, his expected information value from patronizing firm 1 is

$$
\begin{aligned}
\left(1-\frac{\alpha_{1} \mu_{1}}{2}\right)\left(-\frac{1}{16}\right) & +\left(\frac{\alpha_{1} \mu_{1}}{2}\right)\left[\left(2-\frac{1}{\mu_{1}}\right)\left(-\frac{1}{16}\right)+\left(\frac{1}{\mu_{1}}-1\right)(0)\right] \\
& =-\frac{1}{16}+\frac{\alpha_{1}}{32}\left(1-\mu_{1}\right),
\end{aligned}
$$

where the first term is the expected benefit if he does not meet another agent $m$, the second term is the expected benefit if he observes an uninformative $m$, and the last term is the expected benefit if he observes an informative $m$.

Since $\mu_{2}=1-\mu_{1} \leq \frac{1}{2}$, a customer of firm 2 knows that meeting any $m$ of type $\left(\theta_{1}, \theta_{3}\right)$ is fully informative, so his expected information value from patronizing firm 2 is

$$
\begin{aligned}
\left(1-\frac{\alpha_{2} \mu_{2}}{2}\right)\left(-\frac{1}{16}\right) & -\left(\frac{\alpha_{2} \mu_{2}}{2}\right)(0) \\
& =-\frac{1}{16}+\frac{\alpha_{2}}{32}\left(\mu_{2}\right) .
\end{aligned}
$$

Thus, there is a non-monotonic relationship between the equilibrium information value from patronizing a firm and its market share $\mu$, depicted in Figure 4. This hump-shaped relationship arises endogenously due to the trade-off between search cost and signal dilution, since having a larger community increases the ease of communication but agents cannot observe others' preferences perfectly.

Since $\mu_{1}+\mu_{2}=1$, marginal consumers' indifference conditions can be described by:

$$
p_{1}+\left(\frac{\mu_{1}}{2}\right)^{2}-\frac{\alpha_{1}}{32}\left(1-\mu_{1}\right)=p_{2}+\left(\frac{1}{2}-\frac{\mu_{1}}{2}\right)^{2}-\frac{\alpha_{2}}{32}\left(1-\mu_{1}\right),
$$


so firm 1's demand when the investment level is endogeneous, $\mu_{1}^{E I}$, is

$$
\mu_{1}^{E I}=\frac{\alpha_{1}-\alpha_{2}+8}{\alpha_{1}-\alpha_{2}+16}+\frac{32\left(p_{2}-p_{1}\right)}{\alpha_{1}-\alpha_{2}+16}
$$

The first term of Equation (6) indicates that firm 1 would have a larger market share if prices were equal. The second indicates that demand is less sensitive to the price differential than it is in the standard case when meeting technologies do not exist, which is equivalent to no investment by either firm $\left(\alpha_{1}=\alpha_{2}=0\right)$. Neither of these features is surprising, since firm 1 has the technological advantage. But the fact that the information benefit of social interaction is determined by consumers' equilibrium behavior, rather than exogenous, is the reason that price competition is directly weakened by the difference in the effectiveness of meeting technologies. Firm 1 can raise its prices to some extent without decreasing the total value of its bundled good, because the information benefit from patronizing firm 1 actually increases when market share decreases at the margin. That is, firm 1's product is so popular that its customer base contains a subset whose taste is too divergent from the others' and crowds out the information offered by their diametric counterparts. Increasing the price of its product decreases the size of this fringe so that the remaining customer base is more homogeneous in taste. For this reason, the information value of the meeting technology increases for these customers and they are willing to pay a higher price for it. Hence, firm 1 's price elasticity of demand, $\epsilon_{11}^{E I}$ decreases as the technology gap $\left(\alpha_{1}-\alpha_{2}\right)$ between the two firms widens, so firm 1's markup will be higher:

$$
\epsilon_{11}^{E I}=\frac{4 p_{1}}{4\left(p_{2}-p_{1}\right)+1+\frac{1}{8}\left(\alpha_{1}-\alpha_{2}\right)} .
$$

The information value of firm 1's good decreases in market share at the margin is due to the combination of two factors. First, the specified correlation structure implies that signal dilution occurs whenever a firm's market share is greater than $\frac{1}{2}$. Second, the duopoly setting implies that the investing firm will have a market share that exceeds $\frac{1}{2}$. When either of these conditions does not hold, then the information benefit will not decrease with market share at the margin. More generally, this phenomenon occurs whenever alternative correlation and market structures are specified such that signal dilution increases with market share and occurs at the margin, such as if tastes are very localized relative to the number of firms in the market. 


\subsection{Prices}

Given demand, firm 1 chooses price to maximize profit, taking $p_{2}$ as given:

$$
\max _{p_{1}}\left(p_{1}-c\right)\left(\frac{\alpha_{1}-\alpha_{2}+8}{\alpha_{1}-\alpha_{2}+16}+\frac{32\left(p_{2}-p_{1}\right)}{\alpha_{1}-\alpha_{2}+16}\right)-c_{\alpha} \alpha_{1}^{2}
$$

Verifying the second order condition, we obtain

$$
p_{1}=\frac{1}{2}\left[p_{2}+c+\frac{1}{4}+\frac{1}{32}\left(\alpha_{1}-\alpha_{2}\right)\right]
$$

Likewise, firm 2 maximizes profit, where $\mu_{2}^{E I}=1-\mu_{1}^{E I}$, to obtain

$$
p_{2}=\frac{1}{2}\left[p_{1}+c+\frac{1}{4}\right]
$$

Hence, the Nash equilibrium in prices is $p_{1}^{E I}=c+\frac{1}{4}+\frac{1}{48}\left(\alpha_{1}-\alpha_{2}\right)$ and $p_{2}^{E I}=c+\frac{1}{4}+\frac{1}{96}\left(\alpha_{1}-\alpha_{2}\right)$. Firms' market shares are $\mu_{1}^{E I}=\frac{2}{3}\left(\frac{\alpha_{1}-\alpha_{2}+12}{\alpha_{1}-\alpha_{2}+16}\right)$ and $\mu_{2}^{E I}=\frac{1}{3}\left(\frac{\alpha_{1}-\alpha_{2}+24}{\alpha_{1}-\alpha_{2}+16}\right)$, where we can easily verify that $\mu_{1}^{E I} \geq \frac{1}{2} \geq \mu_{2}^{E I}$ when $\alpha_{1} \geq \alpha_{2} \cdot{ }^{9}$ Despite the presence of signal dilution that arises from its majority share, the firm with stronger meeting technology charges a higher price.

\subsection{Investment}

Given equilibrium prices and demand, the firms' total profits $\Pi_{n}^{E I}$ as functions of investment are as follows:

$$
\begin{aligned}
& \Pi_{1}^{E I}=\frac{1}{72}\left(\frac{\left(\alpha_{1}-\alpha_{2}+12\right)^{2}}{\alpha_{1}-\alpha_{2}+16}\right)-c_{\alpha} \alpha_{1}^{2} \\
& \Pi_{2}^{E I}=\frac{1}{288}\left(\frac{\left(\alpha_{1}-\alpha_{2}+24\right)^{2}}{\alpha_{1}-\alpha_{2}+16}\right)-c_{\alpha} \alpha_{2}^{2}
\end{aligned}
$$

Since $\alpha_{1} \geq \alpha_{2}$, the first terms of both $\Pi_{1}^{E I}$ and $\Pi_{2}^{E I}$ are strictly increasing in $\alpha_{1}$ and strictly decreasing in $\alpha_{2}$. Given that increasing $\alpha_{2}$ is also costly (and even if it is costless!), firm 2 's optimal investment choice is $\alpha_{2}^{*}=0$. Why firm 2 makes this somewhat counterintuitive decision becomes evident by decomposing its profit:

$$
\frac{d \Pi_{2}^{E I}}{d \alpha_{2}}=\left(p_{2}^{E I}-c\right)\left(\frac{\partial \mu_{2}^{E I}}{\partial \alpha_{2}}+\frac{\partial \mu_{2}^{E I}}{\partial p_{1}} \frac{d p_{1}^{E I}}{d \alpha_{2}}\right)-2 c_{\alpha} \alpha_{2} .
$$

\footnotetext{
${ }^{9}$ In Appendix A.4, I show that $\mu_{1}^{E I} \geq \mu_{2}^{E I}$ and $\alpha_{1}<\alpha_{2}$ cannot hold simultaneously.
} 
Using equilibrium demand and prices, I obtain

$$
\frac{\partial \mu_{2}^{E I}}{\partial \alpha_{2}}=\frac{\alpha_{1}-\alpha_{2}+24}{3\left(\alpha_{1}-\alpha_{2}+16\right)^{2}}>0
$$

and

$$
\frac{\partial \mu_{2}^{E I}}{\partial p_{1}} \frac{d p_{1}^{E I}}{d \alpha_{2}}=-\frac{2}{3\left(\alpha_{1}-\alpha_{2}+16\right)}<0 .
$$

Equation (7) is the demand effect, where increasing $\alpha_{2}$ directly increases firm 2's demand by increasing its expected informational benefits. Equation (8) is the strategic effect, where increasing $\alpha_{2}$ indirectly decreases firm 2's demand by causing its competitor to lower its price. When $\alpha_{2}$ increases, then firm 1's technological advantage diminishes, so demand is relatively more responsive to prices and price competition intensifies. Here, the incentive to weaken price competition is stronger than the incentive to increase demand, so $\frac{d \Pi_{2}^{E I}}{d \alpha_{2}}<0$. The relaxation of price competition through increased technological differentiation is also the reason that $\frac{d \Pi_{2}^{E I}}{d \alpha_{1}}>0$. In Appendix A.6.4, I also show that firm 2 has no incentive to deviate by choosing an $\alpha_{2}^{\prime}$ such that $\alpha_{2}^{\prime}>\alpha_{1}$.

Proposition 3 Only one firm invests in a meeting technology, and its optimal investment is weakly decreasing in the cost of technological improvements. In particular, there exists a cost $\underline{c}_{\alpha}$ and an upper bound $\bar{\alpha}_{1}$ such that the investing firm chooses $\alpha_{1}^{*}=\bar{\alpha}_{1}$ if $0<c_{\alpha} \leq \underline{c}_{\alpha}$ and a unique $\alpha_{1}^{*}\left(c_{\alpha}\right) \in\left(0, \bar{\alpha}_{1}\right)$ if $c_{\alpha}>\underline{c}_{\alpha}$, where $\alpha_{1}^{*}\left(c_{\alpha}\right)$ is strictly decreasing in $c_{\alpha}$.

Unsurprisingly, the firm's investment in a meeting technology is inversely related to its cost. Investment is increasingly costly and the probability that a consumer learns from others is bounded above by one, so firm 1 never invests such that $\alpha_{1} \mu_{1}>1$. Thus, there exists an upper bound on equilibrium technological strength, $\alpha_{1}$, even if the cost of investment is low. But since it is never an equilibrium for neither firm to invest, it is clear that firm 1 chooses some $\alpha_{1}^{*}>0$ for any finite $c_{\alpha}$ (Appendix A.6).

Hence, there exists no equilibrium in which both firms choose to invest in meeting technology, even if investment is costless, because the incentive to weaken price competition dominates. The investing firm possesses a good that is bundled with a coordination service whose premium over its competitor arises from information-sharing among consumers who wish to identify others with similar tastes, while the other firm sells a good without the added benefit of social interaction. 


\subsection{Welfare}

When only one firm invests, both firms charge higher prices than in the no-investment case. The investing firm is better off, since it can charge a higher price and claim a larger share of the market. Since investing in meeting technology is optimal given that the other does not invest, the investing firm's profit must be strictly greater than in the no-investment case. Customers of the non-investing firm are definitely worse off, since they pay a higher price for the same good. However, it is not obvious how the non-investing firm and customers of the investing firm are affected.

Proposition 4 Although total welfare increases, all consumers are strictly worse off and both firms are strictly better off in the duopoly setting relative to when no social learning occurs. On average, customers of the investing firm are better off than customers of the non-investing firm.

Firm 2's profit is

$$
\Pi_{2}^{E I}=\frac{1}{288}\left(\frac{\left(\alpha_{1}^{*}+24\right)^{2}}{\alpha_{1}^{*}+16}\right)
$$

which exceeds its profit of $\frac{1}{8}$ in the no-investment case whenever $\alpha_{1}^{*}>0$. Hence, the benefits from softened price competition outweigh the loss of market share.

Consumer surplus for patrons of firm 1 equals the aggregate benefits derived from good $x_{11}$ minus the aggregate costs. Here, the aggregate benefit is the sum of the utility derived from good $x_{11}$ and the information value derived from patronizing a firm that offers the coordination service. The aggregate cost is the sum of the price paid and the transportation cost incurred by consumers. In the no-investment case, there is no information value derived from good $x_{11}$, so total consumer surplus is simply $C S^{N I}=v-\left(c+\frac{1}{4}\right)-\frac{1}{48}=v-c-\frac{13}{48} \cdot{ }^{10}$

When only firm 1 invests, consumer surplus for customers of firm 1 , denoted as $C S_{1}^{E I}$, is

$$
\begin{aligned}
C S_{1}^{E I} & =\mu_{I}^{E I}\left[v-p_{I}^{E I}+\frac{\alpha_{1}^{*}}{32}\left(1-\mu_{1}^{E I}\right)\right]-2 \int_{0}^{\frac{\mu_{I}^{E I}}{2}} y^{2} d y \\
& =\mu_{I}^{E I}\left[v-\left(c+\frac{1}{4}\left(1+\frac{\alpha_{1}^{*}}{12}\right)\right)+\frac{\alpha_{1}}{32}\left(1-\mu_{I}^{E I}\right)\right]-\frac{\left(\mu_{I}^{E I}\right)^{3}}{12}
\end{aligned}
$$

\footnotetext{
${ }^{10}$ When neither firm invests, the two agents who lie at the midpoint between the two firms' locations must travel the maximal distance of $\frac{1}{4}$ to buy the good. Hence, the aggregate transportation cost is given by $4 \int_{0}^{\frac{1}{4}} x^{2} d x=\frac{1}{48}$.
} 
In contrast, the surplus of these consumers in the no-investment case, denoted $C S_{1}^{N I}$, is

$$
\begin{aligned}
C S_{1}^{N I} & =\mu_{1}^{E I}\left(v-p^{N I}\right)-2 \int_{0}^{\frac{1}{4}} y^{2} d y-2 \int_{\frac{\mu_{2}^{E I}}{2}}^{\frac{1}{4}} y^{2} d y \\
& =\mu_{1}^{E I}\left(v-\left(\frac{1}{4}+c\right)\right)-\frac{1}{48}+\frac{\left(\mu_{2}^{E I}\right)^{3}}{12}
\end{aligned}
$$

where $\mu_{2}^{E I}<\frac{1}{2}<\mu_{1}^{E I}$. Comparing the two, we find that $C S_{1}^{E I}<C S_{1}^{N I}$ for all $\alpha_{1}>0$. Firm 1 is actually able to extract more than the information value from its customers, because it is the monopolist over a bundle (the good and its meeting technology) whose information value is decreasing in market share at the margin. Holding transportation costs constant, customers of firm 1 are relatively better off than those of firm 2, even though they have lost surplus. The information benefit from buying variety $x_{11}$ rather than $x_{12}$ is

$$
\frac{\alpha_{1}^{*}}{32}\left(1-\mu_{I}^{E I}\right)
$$

while firm 1's additional markup is $\frac{\alpha_{1}^{*}}{48}$, which exceeds the information benefit because $\mu_{I}^{E I}>$ $\frac{1}{2}$. Due to the weakened price competition, firm 2 can charge a markup of $\frac{\alpha_{1}^{*}}{96}$. Thus, absent transportation costs, variety $x_{11}$ is more appealing than $x_{12}$ :

$$
0>\frac{\alpha_{1}^{*}}{32}\left(1-\mu_{I}^{E I}\right)-\frac{\alpha_{1}^{*}}{48}>-\frac{\alpha_{1}^{*}}{96}
$$

Even accounting for transportation costs, the average consumer surplus of firm 1 customers, $\overline{C S}_{1}^{E I}$, exceeds the average consumer surplus of firm 2 customers, $\overline{C S}_{2}^{E I}$ :

$$
\begin{aligned}
& \overline{C S}_{1}^{E I}=C S_{1}^{E I} / \mu_{1}^{E I} \\
& \overline{C S}_{2}^{E I}=\left[\mu_{2}^{E I}\left(v-p_{2}^{E I}\right)-\frac{\left(\mu_{2}^{E I}\right)^{3}}{12}\right] / \mu_{2}^{E I} .
\end{aligned}
$$

Summing together consumer surplus and firms' profits, total surplus is higher when firms can invest in meeting technology than when they cannot, but total consumer surplus is lower. Maximal differentiation in investment weakens price competition to such an extent that the investing firm is able to extract all of its consumers' information surplus through pricing. In addition, the weakened price competition allows the non-investing firm to charge a sufficiently high markup to compensate for its lower market share.

Proposition 5 Relative to the social optimum, firms under-invest in meeting technology in equilibrium. 
I have shown that although consumer welfare decreases as a result of firms' maximal differentiation in technological strength of their coordination services, total surplus increases. However, there is still under-provision of such coordination services relative to the optimum from a social planner's perspective. Because payment for goods is a pure transfer from consumers to firms, the social planner who can select technological investments $\left(\alpha_{1}^{s}, \alpha_{2}^{s}\right)$ to maximize total surplus is concerned with the total information benefits from social interaction at each firm, total transportation costs, and total technological investment costs. Thus, the social planner's problem is:

$$
\max _{\alpha_{1}, \alpha_{2}} \mu_{1}^{E I}\left(\frac{\alpha_{1}}{32}\right)\left(1-\mu_{1}^{E I}\right)+\mu_{2}^{E I}\left(\frac{\alpha_{2}}{32}\right)\left(\mu_{2}^{E I}\right)-2 \int_{0}^{\frac{\mu_{1}^{E I}}{2}} y^{2} d y-2 \int_{0}^{\frac{\mu_{2}^{E I}}{2}} y^{2} d y-c_{\alpha}\left(\alpha_{1}^{2}+\alpha_{2}^{2}\right) .
$$

The solution to the social planner's problem intuitively equates the marginal informational benefits from social interaction to the marginal costs from technological investment, so that $\alpha_{1}^{s}$ and $\alpha_{2}^{s}$ satisfy

$$
\frac{1}{32}\left(1-\mu_{1}^{E I}\right)=2 c_{\alpha}\left(\alpha_{1}^{s}+\alpha_{2}^{s}\right)
$$

where $\mu_{1}^{E I}=\frac{2}{3}\left(\frac{\alpha_{1}^{s}-\alpha_{2}^{s}+12}{\alpha_{1}^{s}-\alpha_{2}^{s}+16}\right)$. Comparing the equilibrium technological investments described in Proposition 3 to the social planner's first-order condition, we can verify that given that firm 2 chooses $\alpha_{2}^{*}=0$, firm 1 under-invests: $\alpha_{1}^{*}<\alpha_{1}^{s}$. The social information benefits from having a stronger meeting technology are strictly increasing in $\alpha_{1}$ despite the presence of signal dilution when market share becomes large. However, firm 1's motive to increase its profit by decreasing price competition with firm 2 leads it to invest in less technological strength than the social planner would. Thus, subsidizing technology investment is a government intervention that would increase both consumer and total surplus.

\subsection{Endogenizing Location}

When both firms simultaneously choose location before choosing technology investment levels and setting prices, they differentiate maximally in location. The full proof with both endogenous location and investment is provided in Appendix A.6.

Proposition 6 In a duopoly where firms choose variety before level of technology investment $\alpha$, the pure strategy equilibrium is such that they differentiate maximally in both location and investment.

1. Firms choose equidistant locations in the product space $\left(d\left(x_{11}, x_{12}\right)=\frac{1}{2}\right)$.

2. For any $c_{\alpha} \geq 0$, one firm chooses $\alpha_{1}^{*}>0$ and the other firm chooses $\alpha=0$. 
3. The investing firm has a larger market share and charges a higher price than the other firm.

4. Total surplus increases, but the meeting technology is underprovided.

5. Both firms are strictly better off than when investment in meeting technology is not possible, while all consumers are strictly worse off.

There exists no equilibrium in which both firms choose to invest in meeting technology, even if investment is costless. Similar to the standard two-stage location-then-price game, firms' incentives to weaken price competition are stronger than the incentive to increase demand, so maximal differentiation in technological strength occurs. However, consumers are worse off and firms are better off than if meeting technology could not exist. Thus, when location, technology investment, and price are endogenous in the duopoly setting, I find that firms differentiate maximally in both location and technological strength.

Investment in technological strength is a form of vertical product differentiation, since all consumers agree on its value. However, its properties differ in key respects from the classic conception, leading to maximal differentiation in both location and social network investment, in contrast to previous results. While vertical differentiation has usually been considered a feature fixed by firms alone (Shaked and Sutton, 1982; Economides, 1993; Dos Santos Ferreira and Thisse, 1996), here a technology's value is determined endogenously by consumers' equilibrium behavior due to the presence of the consumption externality. Moreover, there is a non-monotonic relationship between the information quality and market share of a good that is bundled with a coordination service. For this reason, a technological difference in firms' services directly weakens price competition. The information benefit from patronizing the investing firm actually increases when market share decreases in the relevant region, so the investing firm can raise its prices to some extent without decreasing the information quality of its good. The incentive to weaken price competition is sufficiently strong that firms engage in maximal differentiation in meeting technology, just as in the case of "pure" vertical differentiation (Shaked and Sutton, 1982). In contrast, if there were no consumption externality, then it would have no direct effect on price competition and firms would engage in the "max-min differentation" that has typically been found in other settings with multi-dimensional differentiation. That is, duopoly firms would engage in maximal differentation in one dimension and minimal differentiation in the other, so that they could weaken price competition in the former and increase demand in the latter, as in Economides (1993) and Dos Santos Ferreira and Thisse (1996), which also study firms' decisions when both vertical and horizontal product differentiation are possible. Here, however, the demand effect is weakened due to the presence of a consumption externality such that the value of 
the social network is decreasing as a function of market share at the margin. For this reason, firms engage in maximal differentiation in both the horizontal and vertical dimensions.

In the literature on network externalities, a standard assumption has been that a network externality's value is monotonically increasing in network size, resulting in increased competition in its presence (Katz and Shapiro, 1985; Laffont et al., 1997), because raising price lowers its value. While this assumption is certainly apt to describe a number of settings - including telephones, credit cards, video players, and software platforms - it is less applicable when the externality does not arise from membership in itself. Here, the value of the externality derives from social learning, i.e. interactions within a network, but consumers' preferences are heterogenous, leading to a non-monotonic relationship between the consumption externality's value and market share. Katz and Shapiro (1985) show that consumer surplus is unaffected when all consumers value a network externality equally and a duopoly expands network size through compatibility, and argue that consumer surplus can adversely be affected when consumers' valuations of the externality are heterogeneous. In contrast, I show that the non-monotonic relationship between network size and market share leads to a decrease in consumer surplus even though all consumers value the externality equally. Because the nature of this relationship has been shown here to have a non-trivial impact on pricing decisions, this paper illustrates the importance of endogenizing an externality's value when membership alone is not its central driver.

In a duopoly setting, due to the combination of population correlation in tastes and market structures, the model makes a strong prediction of maximal differentiation in technological strength that is detrimental to consumer welfare, compared to an environment where meeting technology cannot exist. It predicts that consumers should gravitate, for example, to firms that offer goods bundle with meeting technology, and that those firms should consequently have larger market shares and higher prices than counterparts without such services. ${ }^{11}$

The prediction of maximal differentiation in technological strength stems from the fact that the information value of a coordination service is declining in market share at the margin, allowing the investing firm to simultaneously raise its price and increase its coordination service's information value at the expense of consumers. Here, this occurs due to two assumptions, namely the structure of correlated tastes in the population and the presence of a duopoly in the product space. Given the specific population correlation structure posited,

\footnotetext{
${ }^{11}$ Anecdotally, it appears that Netflix and Blockbuster Online, competing online DVD rental services, roughly fit this description a few years ago. Part of the appeal of Netflix was the quality of its user review service, and it tended to attract cinephiles. It had a larger market share and charged higher prices than Blockbuster Online, whose review service was significantly less developed. The addition of streaming services to Netflix, but not Blockbuster, makes the comparison of market shares and prices less straightforward now.
} 
where the service's information value is maximized when it captures half of the market, the coordination service' information value is strictly decreasing at the margin in the duopoly setting, since the investing firm covers the majority of the market in equilibrium. Thus, a relevant question is whether and how this prediction generalizes to other settings. In reality, a market can certainly contain $n>2$ firms, and the correlation in tastes among individuals in the population is almost certainly more localized. While the model's predictions may not hold when there are $n>2$ firms given the specific population correlation structure posited here, the key requirement that a meeting technology's information value be declining in market share at the margin can certainly apply if correlation among agents' tastes is sufficiently localized. The market share threshold at which there is signal dilution from observing a common action lowers as the degree of similarity required for agents to learn from one another increases. If the necessary degree of similarity is sufficiently high, then a coordination service's information value can be declining in market share at the margin when there are $n>2$ firms. Of course, as the number of firms increases, the necessary degree of localization also increases. Though it is unlikely that the model would predict a single coordination service in such a market, the predictions that firms differentiate in meeting technology strength to the detriment of consumers and that investing firms should have larger market shares as well as higher prices than their non-investing counterparts are likely to hold.

\section{Conclusion}

This paper offers an information-based explanation for social interaction and considers firms' optimal investment and pricing choices in a duopoly setting. If agents have uncertainty over their tastes but are aware that their tastes are correlated with others in the population, there exists an incentive to communicate with others in order to learn what is best for oneself. When communication is tied to action, similar agents may choose common actions in order to learn from each other. Hence, peer groups endogenously form reference groups by exhibiting conformity of behavior. Because agents have this desire for information, firms have an opportunity to provide mechanisms that facilitate this coordination. I argue that one natural channel for providing this service is bundling it with the goods themselves, since they present an obvious sorting mechanism for heterogeneous tastes. In this way, goods (and firms) can be associated with specific subsets of the population who wish to and can communicate with one another. I show that in a duopoly setting, only one firm chooses to provide this service, because the incentive to weaken price competition is stronger than the incentive to increase demand. Although total surplus increases with the provision of this mechanism, consumer surplus decreases and the meeting technology is underprovided. 
Consumers benefit from learning from one another, but all of this surplus is extracted by the firms through pricing.

Two alternative explanations for desired coordination among agents are conformity, a preference to behave like others, perhaps out of status concerns (Bernheim, 1994), and homophily, a inherent preference for like-minded others. While homophily may be another component of people's preferences, and certainly is another reason that people engage in social interaction, the prevalence of social media marketing suggests that learning about others' tastes in other dimensions is also important. The need or desire to do so due to homophily is arguably less obvious. While conformity in the presence of subcultures (Bernheim, 1994) can also generate similar results, this paper offers an information-based, rather than preferencebased, explanation for the same phenomenon. Conformity and learning motives could be distinguished by examining whether behavior differs when actions in other dimensions are public or private information. Conformity predicts a disinterest in information about others in other dimensions when one's own actions in such dimensions are private, while homophily predicts that such information is valued in both cases.

A brand, such as a distinctive logo or style, is another type of investment that is bundled with a firm's good and can thus serve as a coordination device for consumers to recognize others with similar tastes. In this context, this paper can also help explain understand how and why groups of individuals with similar tastes across multiple dimensions, which we can interpret as similar identities, can converge on a single good and thus form a "brand community." That is, they share a clear common identity (i.e., set of tastes) and communicate with one another through their consumption choices. An interesting avenue for further pursuit is to consider the supply side of branding: how and why firms could more actively target their brands to specific communities in order to create "lifestyle brands" that embody certain identities and how this affects consumer welfare. For example, Nike is strongly associated with an athlete subculture and also actively markets itself as such.

The coordination service provided by firms in this model is similar to certain features of social networking services, such as Facebook. However, the reality is that Facebook users rarely pay for the use of these widgets; in general, Facebook widgets aim instead to earn revenue through advertisers, who may pay for exposure to specific groups of users through the widgets. Extending the model to a two-sided market structure, such that the widget creator acts as an intermediary to link advertisers to specific groups of users and prices accordingly, is an interesting direction for further research. 


\section{A Appendix}

\section{A.1 Imperfect Correlation}

Suppose that the correlation among agents' tastes is not necessarily perfect. I will show that noisier information has the same qualitative effect as decreasing parameter $\alpha$.

Let $\rho$ be fixed ex ante and known to the agent, where $\rho \in[0,1]$. Nature determines the realized state, by drawing from $P\left(d\left(\theta_{1}, \theta_{3}\right)=0\right)=\{\rho, 1-\rho\}$ with equal probability, where $P\left(d\left(\theta_{1}, \theta_{3}\right)=\frac{1}{2}\right)=1-P\left(d\left(\theta_{1}, \theta_{3}\right)\right.$. In the perfect correlation case studied in the main text, Nature can only select among $\rho \in\{0,1\}$ with equal probability.

First, suppose that $\mu_{1} \leq \frac{1}{2}$. Upon observing the actions of another agent $m$, agent $i$ 's posterior is either $P\left(d\left(\theta_{1}, \theta_{3}\right)=0\right)=\rho$ or $P\left(d\left(\theta_{1}, \theta_{3}\right)=0\right)=1-\rho$. In the former case, agent $i$ chooses $t_{3}=d\left(\theta_{1}, \theta_{3}\right)$ to solve

$$
\max _{t_{3}}-\rho\left(t_{3}\right)^{2}-(1-\rho)\left(\frac{1}{2}-t_{3}\right)^{2}
$$

for which the solution is $t_{3}=\frac{1}{2}(1-\rho)$ and the expected payoff is $-\frac{1}{4} \rho(1-\rho)$. In the latter case, agent $i$ chooses $t_{3}$ to solve

$$
\max _{t_{3}}-(1-\rho)\left(t_{3}\right)^{2}-\rho\left(\frac{1}{2}-t_{3}\right)^{2}
$$

for which the solution is $t_{3}=\frac{1}{2} \rho$ and the expected payoff is $-\frac{1}{4} \rho(1-\rho)$. Therefore, his expected benefit from pooling is

$$
\begin{aligned}
& \left(1-\frac{\alpha \mu_{1}}{2}\right)\left(-\frac{1}{16}\right)+\frac{\alpha \mu_{1}}{2}\left(-\frac{1}{4} \rho(1-\rho)\right) \\
& =-\frac{1}{16}+\frac{\alpha \mu_{1}}{2}\left[\frac{1}{16}-\frac{1}{4} \rho(1-\rho)\right] .
\end{aligned}
$$

Clearly, as $\rho \rightarrow \frac{1}{2}$ from the right or the left, the second term decreases, which is the same qualitative effect as decreasing $\alpha$. Formally, for any pair $(\alpha, \rho)$, there exists a one-to-one mapping between $(\hat{\alpha}, 0)$ (or symmetrically $(\hat{\alpha}, 1))$ and $(\alpha, \rho)$, where $\hat{\alpha}<\alpha$ when $\rho \in(0,1)$ :

$$
\hat{\alpha}=\alpha(1-4 \rho(1-\rho)) .
$$

Second, suppose that $\mu_{1}>\frac{1}{2}$. When $\mu_{1}>\frac{1}{2}$, there is a proportion, $\frac{2\left(\mu_{1}-\frac{1}{2}\right)}{\mu_{1}}=2-\frac{1}{\mu_{1}}$, of $m$ 's from whom observing their actions yields no new information about the true state. Then the probability that $i$ receives useful information is $1-\left(2-\frac{1}{\mu_{1}}\right)=1-\frac{1}{\mu_{1}}$. Hence, his 
expected benefit from pooling is

$$
\begin{aligned}
& \left(1-\frac{\alpha \mu_{1}}{2}\right)\left(-\frac{1}{16}\right)+\frac{\alpha \mu_{1}}{2}\left[\left(2-\frac{1}{\mu_{1}}\right)\left(-\frac{1}{16}\right)+\left(1-\frac{1}{\mu_{1}}\right)\left(-\frac{1}{4} \rho(1-\rho)\right)\right] \\
& =-\frac{1}{16}+\frac{\alpha}{32}\left(1-\mu_{1}\right)(1-4 \rho(1-\rho)) .
\end{aligned}
$$

As $\rho \rightarrow \frac{1}{2}$ from the right or the left, the second term decreases, which is the same qualitative effect as decreasing $\alpha$. Hence, increasing the noisiness of the information is equivalent to decreasing $\alpha$. We can again verify that there is a one-to-one mapping between $(\hat{\alpha}, 0)$ and $(\alpha, \rho)$, where $\hat{\alpha}$ is given by Equation $(11)$.

Since $\rho$ only affects the expected information value of pooling, then the left-hand sides of Equations (2) and (3) are replaced by the term $\frac{\alpha \mu_{1}}{2}\left[\frac{1}{16}-\frac{1}{4} \rho(1-\rho)\right]$, so the stable pooling equilibrium pool size is given by

$$
\mu_{1}\left(x_{1}\right)=\alpha\left(\frac{1}{8}-\frac{1}{2} \rho(1-\rho)\right)
$$

Unsurprisingly, the equilibrium pool size decreases in $\rho(1-\rho)$, the noisiness of information. Maximum equilibrium pool size is now described by Equation $(12)$ and $d\left(x_{1}, x_{1}^{\prime}\right)$ is half this value, but all qualitative results of Proposition 1 apply. Note that none of the claims required to prove Proposition 1 rely on $\mu_{1}\left(x_{1}\right)=\frac{\alpha}{8}$ per se. When $\rho \in(0,1)$, Claim 2 can be applied using $(\hat{\alpha}, 0)$.

\section{A.2 Stability of Pooling Equilibria}

A stable solution for pooling at any given $x_{1}$ must be robust to slight perturbations. In particular, I convert the static equilibrium into a dynamic system to check the stability of the equilibria, where location $x_{1}$ is taken as given:

$$
\begin{aligned}
& \dot{\bar{\theta}}_{1}\left(x_{1}\right)=x_{1}+\sqrt{\alpha\left(\frac{1}{32}\right)\left(\bar{\theta}_{1}-\underline{\theta}_{1}\right)}-\bar{\theta}_{1} \\
& \dot{\theta}_{1}\left(x_{1}\right)=x_{1}-\sqrt{\alpha\left(\frac{1}{32}\right)\left(\bar{\theta}_{1}-\underline{\theta}_{1}\right)}-\underline{\theta}_{1} .
\end{aligned}
$$

The Jacobian for this system is

$$
J=\left(\begin{array}{cc}
\frac{\alpha}{2}\left(\frac{1}{32}\right)\left[\alpha\left(\frac{1}{32}\right)\left(\bar{\theta}_{1}-\underline{\theta}_{1}\right)\right]^{-\frac{1}{2}}-1 & -\frac{\alpha}{2}\left(\frac{1}{32}\right)\left[\alpha\left(\frac{1}{32}\right)\left(\bar{\theta}_{1}-\underline{\theta}_{1}\right)\right]^{-\frac{1}{2}} \\
-\frac{\alpha}{2}\left(\frac{1}{32}\right)\left[\alpha\left(\frac{1}{32}\right)\left(\bar{\theta}_{1}-\underline{\theta}_{1}\right)\right]^{-\frac{1}{2}} & \frac{\alpha}{2}\left(\frac{1}{32}\right)\left[\alpha\left(\frac{1}{32}\right)\left(\bar{\theta}_{1}-\underline{\theta}_{1}\right)\right]^{-\frac{1}{2}}-1
\end{array}\right)
$$

Evaluating the Jacobian at the pooling solution from Equation (4), I obtain eigenvalues 
that are strictly negative, so the solution is stable. Evaluating the Jacobian at the separating solution $\underline{\theta}_{1}=x_{1}=\bar{\theta}_{2}$, I obtain one eigenvalue that is strictly positive and another that is strictly negative, so the solution is unstable.

\section{A.3 Proof of Proposition 1}

I eliminate all other pooling equilibria by proving a series of claims to rule out various classes of equilibria, then consider the remaining type of pooling configuration.

Claim 1 In a given action space, the point at which an interval of agents pool must lie inside that interval. No pool can be composed of disjoint intervals, and no pools overlap.

\section{Proof.}

Consider an interval of agents $\left[\underline{\theta}_{1}, \bar{\theta}_{1}\right]$ that pool at some $x_{1}$. Suppose $x_{1}$ lies outside this interval, $x_{1} \notin\left[\underline{\theta}_{1}, \bar{\theta}_{1}\right]$. Then there exists some $\theta_{1}^{\prime} \in\left[x_{1}, \underline{\theta}_{1}\right)$ such that the $\theta_{1}^{\prime}$ agent prefers not to join the pool, even though his travel costs to pool are strictly lower than that of the $\underline{\theta}_{1}$ agent and the information benefits are the same. This cannot hold simultaneously in equilibrium. Thus, an interval of agents $\left[\underline{\theta}_{1}, \bar{\theta}_{1}\right]$ must be pooling at an $x_{1} \in\left[\underline{\theta}_{1}, \bar{\theta}_{1}\right]$.

Suppose that the set of agents that pool at $x_{1}$ is the union of two disjoint intervals, $\left[\underline{\theta}_{1}, \bar{\theta}_{1}\right] \cup\left[\underline{\theta}_{1}^{\prime}, \bar{\theta}_{1}^{\prime}\right]$, where $\left[\underline{\theta}_{1}, \bar{\theta}_{1}\right] \cap\left[\underline{\theta}_{1}^{\prime}, \bar{\theta}_{1}^{\prime}\right]=\emptyset$. Without loss of generality, suppose $x_{1} \in\left[\underline{\theta}_{1}, \bar{\theta}_{1}\right]$. Since $x_{1}$ lies outside $\left[\underline{\theta}_{1}^{\prime}, \bar{\theta}_{1}^{\prime}\right]$, then we can apply the same argument as above to rule out this possibility.

Suppose that two pools overlap. For example, let agents in the interval $\left[\underline{\theta}_{1}, \bar{\theta}_{1}\right]$ pool at $x_{1} \in\left[\underline{\theta}_{1}, \bar{\theta}_{1}\right]$ and agents in the interval $\left[\underline{\theta}_{1}^{\prime}, \bar{\theta}_{1}^{\prime}\right]$ pool at $x_{1}^{\prime} \in\left[\underline{\theta}_{1}^{\prime}, \bar{\theta}_{1}^{\prime}\right]$, where $\left[\underline{\theta}_{1}, \bar{\theta}_{1}\right] \cap\left[\underline{\theta}_{1}^{\prime}, \bar{\theta}_{1}^{\prime}\right] \neq \emptyset$ . Any agent whose type lies the interval $\left[\underline{\theta}_{1}, \bar{\theta}_{1}\right] \cap\left[\underline{\theta}_{1}^{\prime}, \bar{\theta}_{1}^{\prime}\right]$ and pools at $x_{1}$ would incur strictly lower travel costs to pool at $x_{1}^{\prime}$ and enjoy the same benefits as the $\underline{\theta}_{1}^{\prime}$ type, who prefers to pool at $x_{1}^{\prime}$, which is not possible. Thus, no pools can overlap.

Second, no pool exists such that $\mu_{1}\left(x_{1}\right)>\frac{1}{2}$.

Claim 2 When $\alpha \mu_{1} \leq 1$, then $\mu_{1} \leq \frac{1}{2}$.

\section{Proof.}

Suppose that a pool at $x_{1}$ exists such that $\mu_{1}\left(x_{1}\right)>\frac{1}{2}$. With probability $1-\frac{\eta_{1}}{2}$, a customer of firm 1 acquires no new information about his own tastes, because he either meets no one or he meets another $\left(\theta_{1}, \theta_{2}\right)$ agent, from whom he learns nothing about $\theta_{3}$. In this case, he chooses an action such that $d\left(\theta_{1}, \theta_{3}\right)=\frac{1}{4}$ and his expected payoff is $v_{3}-\left(\frac{1}{4}\right)^{2}$. With probability $\frac{\eta_{1}}{2}$, he meets an agent $m$ of type $\left(\theta_{1}, \theta_{3}\right)$ who chose $x_{1}$. If he observes $m$ 's actions $\left(\mathbf{x}^{m}\right)$, then he must account for the possibility that he encounters an $m$ whose tastes differ too much 
to yield useful information. When $\mu_{j}>\frac{1}{2}$, there is a proportion, $\frac{2\left(\mu_{1}-\frac{1}{2}\right)}{\mu_{1}}=2-\frac{1}{\mu_{1}}$, of $\mathrm{m}$ 's from whom observing their actions yields no new information about the true state. Because $\mu_{1}>\frac{1}{2}$, then observing such an $m$ 's choice of $x_{3}$ is uninformative because it is equally likely that $d\left(\theta_{1}, x_{3}\right)=0$ or $d\left(\theta_{1}, x_{3}\right)=\frac{1}{2}$, as both types of consumers have chosen the same $x_{1}$. In this event, the agent faces the same problem as when he doesn't meet any other consumer, so his expected payoff is $v_{3}-\left(\frac{1}{4}\right)^{2}$. However, there is also a proportion, $1-\left(2-\frac{1}{\mu_{1}}\right)=\frac{1}{\mu_{1}}-1$, of $m$ 's from whom observing their actions allows the consumer to perfectly infer his own taste. In this event, his expected payoff is $v_{3}-0$, since he can then select $x_{3}=\theta_{3}$ in the second period. Therefore, his expected information value from patronizing firm 1 is

$$
\begin{aligned}
\left(1-\frac{\alpha_{1} \mu_{1}}{2}\right)\left(-\frac{1}{16}\right) & +\left(\frac{\alpha_{1} \mu_{1}}{2}\right)\left[\left(2-\frac{1}{\mu_{1}}\right)\left(-\frac{1}{16}\right)+\left(\frac{1}{\mu_{1}}\right)(0)\right] \\
& =-\frac{1}{16}+\frac{\alpha_{1}}{32}\left(1-\mu_{1}\right)
\end{aligned}
$$

where the first term is the expected benefit if he does not meet another agent $m$, and the next two terms are the expected benefit if he observes an uninformative $m$, and the last term is the expected benefit if he observes an informative $m$. As before, I require that $\eta_{1}=\alpha \mu_{1} \leq 1$. Pooling surplus must be non-negative for all agents in the pool in equilibrium, which reduces to the following condition:

$$
\left(\theta_{1}-x_{1}\right)^{2} \leq \frac{\alpha}{32}\left(1-\mu_{1}\right)
$$

When $\mu_{1}>\frac{1}{2}$, then there exists some $\theta_{1}$ in the pool such that $d\left(x_{1}-\theta_{1}\right)=\frac{1}{4}$ and surplus is non-negative. From (15), this implies that for such an agent,

$$
\frac{\alpha}{32}\left(1-\mu_{1}\right)>\left(\theta_{1}-x_{1}\right)^{2}=\frac{1}{16}
$$

Since $\alpha \mu_{1} \leq 1$, then this requires that $2 \mu_{1} \leq 1-\mu_{1}$, which cannot be true when $\mu_{1}>\frac{1}{2}$. Hence, $\mu_{1} \leq \frac{1}{2}$ when $g(\cdot)$ is a symmetric quadratic loss function with $\alpha \mu_{1} \leq 1$.

Third, the composition of a pool is always "symmetric-by-types" in the following sense.

Claim 3 For any pool at a given point in an action space $X_{j}$, agents of differing information types pool symmetrically. For example, suppose that $\bar{\theta}_{1}^{a}\left(x_{1}\right)$ and $\underline{\theta}_{1}^{a}\left(x_{1}\right)$ are the marginal agents with information $\left(\theta_{1}, \theta_{2}\right)$ who pool at $x_{1}$, and $\bar{\theta}_{1}^{b}\left(x_{1}\right)$ and $\underline{\theta}_{1}^{b}\left(x_{1}\right)$ are the marginal agents with information $\left(\theta_{1}, \theta_{3}\right)$ who pool at $x_{1}$. Then $\bar{\theta}_{1}^{a}\left(x_{1}\right)=\bar{\theta}_{1}^{b}\left(x_{1}\right)$ and $\underline{\theta}_{1}^{a}\left(x_{1}\right)=\underline{\theta}_{1}^{b}\left(x_{1}\right)$.

Proof. To prove this claim, I will show that $\mu_{1}^{a}\left(x_{1}\right)=\mu_{1}^{b}\left(x_{1}\right)$. Due to the symmetry of the circular model, there is clearly a unique solution $\left(\underline{\theta}_{j}\left(x_{j}\right), \bar{\theta}_{j}\left(x_{j}\right)\right)$ for any $\mu_{j}\left(x_{j}\right)$, so showing 
that $\mu_{1}^{a}\left(x_{1}\right)=\mu_{1}^{b}\left(x_{1}\right)$ is sufficient to establish the claim.

Suppose that $\mu_{1}^{a}\left(x_{1}\right) \neq \mu_{1}^{b}\left(x_{1}\right)$. Without loss of generality, let $\mu_{1}^{a}\left(x_{1}\right)<\mu_{1}^{b}\left(x_{1}\right)$. This implies that for the same location, there are $\left(\theta_{1}, \theta_{3}\right)$ agents who are willing to incur a larger cost to pool for a relatively lower expected benefit from information, while there are $\left(\theta_{1}, \theta_{2}\right)$ agents who are unwilling to incur a smaller cost to pool for a relatively higher expected benefit from information. Given that $\left(\theta_{1}, \theta_{2}\right)$ and $\left(\theta_{1}, \theta_{3}\right)$ agents face an identical optimization problem, this cannot hold in equilibrium. Therefore, $\mu_{1}^{a}\left(x_{1}\right)=\mu_{1}^{b}\left(x_{1}\right)$ at $x_{1}$.

The following claim demonstrates the $n$-integer problem.

Claim 4 Let $n$ be the number of pools that exist in the action space $X_{1}$. Suppose that the parameter $\alpha$ is a value such that $n$ is not an integer when it satisfies the condition $n\left(\frac{\alpha}{8}\right)=1$. Then there does not exist a stable equilibrium in which all pools have size $\frac{\alpha}{8}$ except the remaining space, where either the remaining agents do not pool anywhere or they form a pool of size less than $\frac{\alpha}{8}$.

Proof. Suppose that there exists some open interval $L$ length $l<\frac{\alpha}{8}$ on $X_{1}$ such that any agent with $\theta_{1} \in L$ does not pool anywhere. Let agents at the endpoints of interval $L$ be denoted $\underline{\theta}_{L}$ and $\bar{\theta}_{L}$. Because the separating equilibrium is not stable, this interval of nonpooling agents is not robust to small perturbations. Without loss of generality, suppose that the agents in this interval pool at some $x_{1}^{L} \in L$. Since $l<\frac{\alpha}{8}$, the requirement that the information benefits of pooling outweigh the costs is clearly satisfied, that is the inequality in Equation (1) is satisfied for all agents in the interval $L$. Furthermore, Equation (1) must hold with inequality for both for the marginal agents $\underline{\theta}_{L}$ and $\bar{\theta}_{L}$, regardless of whether the pool at $x_{1}^{L}$ is symmetric on either side of the point $x_{1}^{L}$. Let $x_{1}$ be the center of a symmetric pool of size $\frac{\alpha}{8}$ adjacent to $x_{1}^{L}$, such that the $\underline{\theta}_{L}$ agent is also the marginal agent for the pool at the point $x_{1}$. By construction, Equation (1) must hold with equality for the $\underline{\theta}_{L}$ agent with respect to pooling at $x_{1}$ rather than not pooling, so there is zero surplus from pooling at $x_{1}$. Likewise, an analogous situation applies to the $\bar{\theta}_{L}$ agent. But since we have just argued that Equation (1) holds with inequality for this agent with respect to pooling at $x_{1}^{L}$, then he cannot be the marginal agent for both pools, since pooling at the point $x_{1}^{L}$ yields strictly positive surplus. Hence, the proposed configuration unravels and cannot exist.

Furthermore, there can exist equilibria in which adjacent symmetric pools are of alternating size, where the distance between any two pooling points is exactly $\frac{\alpha}{16}$.

Claim 5 There can exist an equilibrium in which any two adjacent pooling points $x_{1}$ and $x_{1}^{\prime}$, with pools of size $\mu_{1}\left(x_{1}\right)$ and $\mu_{1}\left(x_{1}^{\prime}\right)$ respectively, are symmetric and either $d\left(x_{1}, x_{1}^{\prime}\right)=\frac{\alpha}{16}$ or the two adjacent pools are identical in size. Furthermore, this is the only configuration for which more than one size of symmetric pool can coexist in equilibrium. 
Proof. Let $x_{1}$ and $x_{1}^{\prime}$ be two adjacent pooling points on the $X_{1}$ space with pool sizes $\mu_{1}\left(x_{1}\right)$ and $\mu_{1}\left(x_{1}^{\prime}\right)$ respectively, and let the marginal agent between the two points be denoted $\bar{\theta}^{\prime}$. Let $d_{1}=d\left(\bar{\theta}^{\prime}, x_{1}\right)$ and $d_{1}^{\prime}=d\left(\bar{\theta}^{\prime}, x_{1}^{\prime}\right)$. Without loss of generality, let $d_{1} \geq d_{1}^{\prime}$. Since each pool is symmetric across its pooling point, then $\mu_{1}\left(x_{1}\right)=2 d_{1}$ and $\mu_{1}\left(x_{1}^{\prime}\right)=2 d_{1}^{\prime}$. Combining this with Equation (1), the marginal $\bar{\theta}^{\prime}$ agent must be indifferent between pooling at $x_{1}$ and $x_{1}^{\prime}$ :

$$
\begin{aligned}
\frac{\alpha \mu_{1}}{32}-\left(\bar{\theta}^{\prime}-x_{1}\right)^{2} & =\frac{\alpha \mu_{1}^{\prime}}{32}-\left(\bar{\theta}^{\prime}-x_{1}^{\prime}\right)^{2} \\
\frac{\alpha}{16}\left(2 d_{1}\right)-\left(d_{1}\right)^{2} & =\frac{\alpha}{16}\left(2 d_{1}^{\prime}\right)-\left(d_{1}^{\prime}\right)^{2} \\
\left(d_{1}-d_{1}^{\prime}\right)\left[d_{1}+d_{1}^{\prime}-\frac{\alpha}{16}\right] & =0 .
\end{aligned}
$$

Therefore, the marginal agent is only indifferent if $d_{1}=d_{1}^{\prime}$ or $d_{1}+d_{1}^{\prime}=\frac{\alpha}{16}$. This implies that two adjacent symmetric pools of unequal size can only exist if their pooling points are spaced exactly $\frac{\alpha}{16}$ apart; otherwise, the adjacent pools must be identical in size. Because this condition must hold for every marginal agent in the $X_{1}$ space, this means that exactly two differing pool sizes can coexist and must alternate in an action space $X_{j}$, and they are bounded above by $\frac{\alpha}{8}$.

\section{A.4 Market Share and Investment}

I rule out the case of $\mu_{1}^{E I} \geq \mu_{2}^{E I}$ and $\alpha_{1}<\alpha_{2}$ simultaneously. Suppose that this holds. Given Equation (6) and that $\mu_{1}^{E I}+\mu_{2}^{E I}=1$, this implies that $\alpha_{1}-\alpha_{2}<-24$. Since $\alpha_{2} \mu_{2} \leq 1$, the highest feasible value of $\alpha_{2}$ is chosen when $\mu_{2}$ is minimized. Given Equation (6) and that $\mu_{1}^{E I}+\mu_{2}^{E I}=1$, the minimal market share that firm 2 can attain is $\frac{1}{3}$. Since $\alpha_{1}$ is minimized at $\alpha_{1}=0$, then $\alpha_{1}-\alpha_{2} \geq-3$. Thus, $\mu_{1}^{E I} \geq \mu_{2}^{E I}$ and $\alpha_{1} \geq \alpha_{2}$.

\section{A.5 Proof of Proposition 3}

Because $\eta_{n}=\min \left\{\alpha_{n} \mu_{n}\left(x_{n}\right), 1\right\}$, firm 1 will never invest in $\alpha_{1}>\bar{\alpha}_{1}$ where $\bar{\alpha}_{1}\left(\mu_{1}^{E I}\right)=1$. Since $\alpha_{2}^{*}=0$ in equilibrium, I obtain an upper bound on equilibrium technological strength, $\bar{\alpha}_{1}:$

$$
\begin{aligned}
\bar{\alpha}_{1}\left(\mu_{1}^{E I}\right) & =1 \\
\bar{\alpha}_{1}\left(\frac{2}{3}\left(\frac{\bar{\alpha}_{1}+12}{\bar{\alpha}_{1}+16}\right)\right) & =1 \\
\bar{\alpha}_{1} & =-\frac{21}{4}+\frac{5}{4} \sqrt{33}(<2) .
\end{aligned}
$$


There may exist $0<\underline{c}_{\alpha}<\bar{c}_{\alpha}$ such that the optimal choice is $\alpha_{1}=\bar{\alpha}_{1}$ if $c_{\alpha} \leq \underline{c}_{\alpha}$ and $\alpha_{1}=0$ if $c_{\alpha}>\bar{c}_{\alpha}$. Then for $\underline{c}_{\alpha}<c_{\alpha}<\bar{c}_{\alpha}$, there is a unique interior solution $\alpha_{1}^{*}\left(c_{\alpha}\right) \in\left(0, \bar{\alpha}_{1}\right)$, where $\alpha_{1}^{*}\left(c_{\alpha}\right)$ is the value of $\alpha_{1}$ such that firm 1's first order condition equals zero, given that $\alpha_{2}^{*}=0$. The first order condition for firm 1 is

$$
\frac{\partial \Pi_{1}^{E I}}{\partial \alpha_{1}}=\frac{1}{72}\left[\frac{\left(\alpha_{1}-\alpha_{2}+12\right)\left(\alpha_{1}-\alpha_{2}+20\right)}{\left(\alpha_{1}-\alpha_{2}+16\right)^{2}}\right]-2 c_{\alpha} \alpha_{1} .
$$

The lower bound $\underline{c}_{\alpha}$ is the maximum $c_{\alpha}$ such that the first order condition is positive for all $\alpha_{1} \in\left[0, \bar{\alpha}_{1}\right]$. This holds for all $c_{\alpha}$ such that

$$
c_{\alpha}<\frac{1}{144}\left[\frac{\left(\alpha_{1}-\alpha_{2}+12\right)\left(\alpha_{1}-\alpha_{2}+20\right)}{\alpha_{1}\left(\alpha_{1}-\alpha_{2}+16\right)^{2}}\right] .
$$

Since $\alpha_{2}^{*}=0$ in equilibrium and the right-hand side is strictly decreasing in $\alpha_{1}$, I evaluate the right-hand side of this expression at $\alpha_{1}=\bar{\alpha}_{1}, \alpha_{2}=0$ to obtain $\underline{c}_{\alpha}$ :

$$
\underline{c}_{\alpha}=\frac{8401}{4718592}+\frac{1345}{4718592}(\sqrt{33}) .
$$

The second-order condition for firm 1 is

$$
\frac{\partial^{2} \Pi_{1}^{E I}}{\partial \alpha_{1}^{2}}=\frac{4}{9\left(\alpha_{1}-\alpha_{2}+16\right)^{3}}-2 c_{\alpha} .
$$

Since $\alpha_{2}^{*}=0$, the second-order condition is negative when

$$
c_{\alpha}>\frac{4}{18\left(\alpha_{1}+16\right)^{3}} \equiv R H S_{2},
$$

where $R H S_{2}$ is strictly decreasing in $\alpha_{1}$. Thus, the second-order condition is unambiguously satisfied when $c_{\alpha}>R H S_{2}\left(\alpha_{1}=0\right)$ :

$$
c_{\alpha}>\frac{4}{18(16)^{3}}=\frac{1}{18432} .
$$

Since $\frac{1}{18432}<\underline{c}_{\alpha}$, then the second-order condition is satisfied for all values of $\alpha_{1}^{*}$ such that $\alpha_{1}^{*}<\bar{\alpha}_{1}$ (i.e., when firm 1's first-order condition equals zero). Thus, firm 1's second-order condition with respect to $\alpha_{1}$ is satisfied for all values of $\alpha_{1}^{*}$ such that $\alpha_{1}^{*}<\bar{\alpha}_{1}$. For values of $c_{\alpha}$ such that $\alpha_{1}^{*}=\bar{\alpha}_{1}$, the first-order condition is strictly positive, so the second-order condition is not relevant.

The upper bound $\bar{c}_{\alpha}$ is the minimum $c_{\alpha}$ such that the first order condition is negative for 
all $\alpha_{1} \in\left[0, \bar{\alpha}_{1}\right]$. This holds for all $c_{\alpha}$ such that

$$
c_{\alpha}>\frac{1}{144}\left[\frac{\left(\alpha_{1}-\alpha_{2}+12\right)\left(\alpha_{1}-\alpha_{2}+20\right)}{\alpha_{1}\left(\alpha_{1}-\alpha_{2}+16\right)^{2}}\right]
$$

But since the right-hand side is unbounded as $\alpha_{1} \rightarrow 0$, then this $\bar{c}_{\alpha}$ does not exist. That is, no matter how finitely large $c_{\alpha}$ is, there always exists an interior solution $\alpha_{1}>0$ (though as $c_{\alpha}$ increases, the optimal $\alpha_{1}$ asymptotically approaches zero). Thus, firm 1 chooses $\alpha_{1}^{*}=\bar{\alpha}_{1}$ if $c_{\alpha} \leq \underline{c}_{\alpha}$ and a unique $\alpha_{1}^{*}\left(c_{\alpha}\right) \in\left(0, \bar{\alpha}_{1}\right)$ if $c_{\alpha}>\underline{c}_{\alpha}$, where $\alpha_{1}^{*}\left(c_{\alpha}\right)$ strictly decreases with $c_{\alpha}$ in this region.

\section{A.6 Endogenizing Location and Investment}

In the previous section, I assumed that firms' locations were equidistant, so that $x_{1}-x_{2}=\frac{1}{2}$. Here, I will demonstrate that the configuration of locations and technologies that exhibits maximal differentiation in both of those dimensions is the unique equilibrium when location is also endogenous. The game becomes a three-stage game in which firms simultaneously choose locations, then technological strengths, and lastly prices.

\section{A.6.1 Timeline}

1. Firms simultaneously choose varieties $x_{1 n}$ (i.e., location), where $x_{1 n} \in S^{1}$ for $n=1,2$.

2. Firms simultaneously choose technologies $\alpha_{n}$, where $n=1,2$ and incur investment $\operatorname{costs} c_{\alpha} \alpha_{n}^{2} \geq 0$ where $c_{\alpha} \geq 0$.

3. Firms simultaneously choose prices $p_{n}, n=1,2$.

4. Observing $x_{1 n}, \alpha_{n}$ and $p_{n}$, where $n=1,2$, consumers choose whether or not to buy $x_{11}$ or $x_{12}$.

5. (Consumers choose to buy goods in other markets/dimensions.)

\section{A.6.2 Demand}

Without loss of generality, suppose that $\alpha_{1} \geq \alpha_{2}, \mu_{1} \geq \mu_{2}$, and let $b=d\left(x_{11}, x_{12}\right)$, where $b \in[0,1]$. The marginal consumers' indifference conditions can be described by the following 
equations:

$$
\begin{aligned}
& p_{1}+\left(\bar{\theta}_{1}-x_{1}\right)^{2}-\frac{\alpha_{1}}{16}\left(1-\mu_{1}\right)=p_{2}+\left(1+x_{2}-\bar{\theta}_{1}\right)^{2}-\frac{\alpha_{2}}{16}\left(\mu_{2}\right) \\
& p_{1}+\left(x_{1}-\underline{\theta}_{1}\right)^{2}-\frac{\alpha_{1}}{16}\left(1-\mu_{1}\right)=p_{2}+\left(\underline{\theta}_{1}-x_{2}\right)^{2}-\frac{\alpha_{2}}{16}\left(\mu_{2}\right),
\end{aligned}
$$

where $\mu_{1}=d\left(\bar{\theta}_{1}, \underline{\theta}_{1}\right)$ and $\mu_{1}+\mu_{2}=1$. Then we can obtain firm 1's demand as

$$
\mu_{1}=\frac{\alpha_{1}-\alpha_{2}+32\left(p_{2}-p_{1}\right)+32 b(1-b)}{\alpha_{1}-\alpha_{2}+64 b(1-b)} .
$$

\section{A.6.3 Prices}

Given demand, firm 1 chooses price to maximize profit, taking $p_{2}$ as given:

$$
\max _{p_{1}}\left(p_{1}-c\right)\left(\frac{\alpha_{1}-\alpha_{2}+32\left(p_{2}-p_{1}\right)+32 b(1-b)}{\alpha_{1}-\alpha_{2}+64 b(1-b)}\right)-c_{\alpha} \alpha_{1}^{2}
$$

Verifying the second order condition, we obtain

$$
p_{1}=\frac{1}{2}\left[p_{2}+c+b(1-b)+\frac{1}{32}\left(\alpha_{1}-\alpha_{2}\right)\right] .
$$

Likewise, firm 2 maximizes profit, where $\mu_{2}=1-\mu_{1}$, to obtain

$$
p_{2}=\frac{1}{2}\left[p_{1}+c+b(1-b)\right]
$$

Hence, the Nash equilibrium in prices is $p_{1}=c+b(1-b)+\frac{1}{48}\left(\alpha_{1}-\alpha_{2}\right)$ and $p_{2}=c+b(1-$ b) $+\frac{1}{96}\left(\alpha_{1}-\alpha_{2}\right)$. Firms' market shares are

$$
\begin{aligned}
\mu_{1} & =\frac{2}{3}\left(\frac{\alpha_{1}-\alpha_{2}+48 b(1-b)}{\alpha_{1}-\alpha_{2}+64 b(1-b)}\right) \\
\mu_{2} & =\frac{1}{3}\left(\frac{\alpha_{1}-\alpha_{2}+96 b(1-b)}{\alpha_{1}-\alpha_{2}+64 b(1-b)}\right) .
\end{aligned}
$$

\section{A.6.4 Investment Choice}

Given equilibrium prices and demand, firms' total profits are as follows:

$$
\begin{aligned}
& \Pi_{1}=\frac{1}{72}\left[\frac{\left(\alpha_{1}-\alpha_{2}+48 b(1-b)\right)^{2}}{\alpha_{1}-\alpha_{2}+64 b(1-b)}\right]-c_{\alpha} \alpha_{1}^{2} \\
& \Pi_{2}=\frac{1}{288}\left[\frac{\left(\alpha_{1}-\alpha_{2}+96 b(1-b)\right)^{2}}{\alpha_{1}-\alpha_{2}+64 b(1-b)}\right]-c_{\alpha} \alpha_{2}^{2}
\end{aligned}
$$




\section{Firm 2}

When $\alpha_{1} \geq \alpha_{2}$, it is clear that the first terms of both $\Pi_{1}^{E I}$ and $\Pi_{2}^{E I}$ are strictly increasing in $\alpha_{1}$ and strictly decreasing in $\alpha_{2}$. Given that increasing $\alpha_{2}$ is also costly (and even if it is costless!), firm 2 optimizes by choosing $\alpha_{2}^{*}=0$.

We can see why firm 2 makes this choice by decomposing its profit. Note that

$$
\frac{d \Pi_{2}}{d \alpha_{2}}=\left(p_{2}-c\right)\left(\frac{\partial \mu_{2}}{\partial \alpha_{2}}+\frac{\partial \mu_{2}}{\partial p_{1}} \frac{d p_{1}}{d \alpha_{2}}\right)-2 c_{\alpha} \alpha_{2}
$$

Using our equilibrium demand and prices, we obtain

$$
\frac{\partial \mu_{2}}{\partial \alpha_{2}}=\frac{1}{3}\left[\frac{\alpha_{1}-\alpha_{2}+96 b(1-b)}{\left(\alpha_{1}-\alpha_{2}+64 b(1-b)\right)^{2}}\right]>0
$$

and

$$
\frac{\partial \mu_{2}}{\partial p_{1}} \frac{d p_{1}}{d \alpha_{2}}=-\frac{2}{3}\left[\frac{1}{\alpha_{1}-\alpha_{2}+64 b(1-b)}\right]<0 .
$$

The first term is the demand effect, where increasing $\alpha_{2}$ directly increases firm 2's demand by increasing its expected informational benefits. The second term is the strategic effect, where increasing $\alpha_{2}$ indirectly decreases firm 2's demand by causing its competitor to lower its price. When $\alpha_{2}$ increases, then firm 1's technological advantage diminishes, so demand is relatively more responsive to prices and price competition intensifies. Summing equations (21) and (22), we find that the strategic effect dominates, so $\frac{d \Pi_{2}^{E I}}{d \alpha_{2}}<0$. The incentive to weaken price competition is stronger than the incentive to increase demand. Likewise, the relaxation of price competition through increased technological differentiation is the reason that $\frac{d \Pi_{2}^{E I}}{d \alpha_{1}}>0$, and firm 2 was better off in the single investment case than in the dual investment case, previously.

\section{Firm 1}

Since the second term of $\Pi_{1}^{E I}$ is decreasing in $\alpha_{1}$, then firm 1's optimal $\alpha_{1}$ depends on $c_{\alpha}$, the degree to which technological improvements are costly. By the same argument from the previous section, in which location was exogenous, firm 1 will choose an optimal $\alpha_{1}^{*}>0$ for any $c_{\alpha} \geq 0$.

Clearly, firm 1 has no incentive to change its choice of $\alpha_{1}^{*}$ given that firm 2 chooses $\alpha_{2}^{*}=0$. I now verify that, for any $c_{\alpha} \geq 0$, firm 2 has no incentive to deviate by choosing an $\alpha_{2}^{\prime}$ such that $\alpha_{2}^{\prime}>\alpha_{1}^{*}$. Suppose that such an $\alpha_{2}^{\prime}$ exists. Then firm 2's best deviation $\alpha_{2}^{\prime}$ is given by

$$
\max _{\alpha_{2}^{\prime}} \frac{1}{72}\left[\frac{\left(\alpha_{2}^{\prime}-\alpha_{1}^{*}+48 b(1-b)\right)^{2}}{\alpha_{2}^{\prime}-\alpha_{1}^{*}+64 b(1-b)}\right]-c_{\alpha}\left(\alpha_{2}^{\prime}\right)^{2},
$$


where we can easily verify that $\frac{\partial \alpha_{2}^{\prime}}{\partial \alpha_{1}^{*}}<0$. But note that $\alpha_{1}^{*}$ was chosen to satisfy:

$$
\max _{\alpha_{1}^{*}} \frac{1}{72}\left[\frac{\left(\alpha_{1}^{*}-\alpha_{2}^{*}+48 b(1-b)\right)^{2}}{\alpha_{1}^{*}-\alpha_{2}^{*}+64 b(1-b)}\right]-c_{\alpha}\left(\alpha_{1}^{*}\right)^{2}
$$

where $\alpha_{2}^{*}=0$. Since $\alpha_{1}^{*}>0$, then this implies that $\alpha_{2}^{\prime}<\alpha_{1}^{*}$, which is a contradiction. Thus, for any $c_{\alpha} \geq 0$, firm 2 has no incentive to deviate by choosing an $\alpha_{2}^{\prime}$ such that $\alpha_{2}^{\prime}>\alpha_{1}^{*}$.

\section{A.6.5 Location}

Given equilibrium investments $\alpha_{1}=\alpha_{1}^{*}$ and $\alpha_{2}=0$, firms simultaneously maximize profit with respect to location:

$$
\begin{aligned}
& \max _{x_{1}}\left\{\frac{1}{72}\left[\frac{\left(\alpha_{1}^{*}+48 b(1-b)\right)^{2}}{\alpha_{1}^{*}+64 b(1-b)}\right]-c_{\alpha} \alpha_{1}^{* 2}\right\} \\
& \max _{x_{2}}\left\{\frac{1}{288}\left[\frac{\left(\alpha_{1}^{*}+96 b(1-b)\right)^{2}}{\alpha_{1}^{*}+64 b(1-b)}\right]\right\},
\end{aligned}
$$

where $b=d\left(x_{11}, x_{12}\right)$. The unique solution for which $b \in[0,1]$ is that $b^{*}=\frac{1}{2}$. Therefore, we obtain that firms differentiate maximally in location. Since $b^{*}=\frac{1}{2}$, then we can refer the results from the previous section, where we had assumed that $b=\frac{1}{2}$, to obtain the equilibrium demands, prices, and investments.

\section{A.6.6 Covered Market Equilibrium}

Finally, I show that the market must be covered when $v$ is sufficiently high. Suppose that there exists an equilibrium in which the market is not covered. I assume symmetry for simplicity (i.e., each firm's marginal consumers are located symmetrically around its location). Note that at least one firm, say firm 1, must have less than half of the market covered. Let $p_{1}^{u}$ be firm 1's optimal price in the uncovered market, and $\mu_{1}^{u}$ be its optimal market share in the uncovered market. Given its choice of $\alpha_{1}=\alpha_{1}^{u}$, firm 1 must be setting $p_{1}$ such that its marginal consumers are indifferent between buying its good and buying nothing:

$$
v-p_{1}^{u}-\left(\frac{1}{2} \mu_{1}^{u}\right)^{2}+\frac{\alpha_{1}^{u} \mu_{1}^{u}}{32}=0
$$

Given Equation 23, it is clear that setting price $p_{1}^{u}$ is equivalent to choosing market share $\mu_{1}^{u}$. Thus, firm 1's profit-maximizing pricing decision satisfies:

$$
\max _{\mu_{1}^{u}}\left(p_{1}^{u}-c\right)\left(\mu_{1}^{u}\right)-c_{\alpha}\left(\alpha_{1}^{u}\right)^{2}=\max _{\mu_{1}^{u}}\left(v-c-\left(\frac{1}{2} \mu_{1}^{u}\right)^{2}+\frac{\alpha_{1}^{u} \mu_{1}^{u}}{32}\right) \mu_{1}^{u}-c_{\alpha}\left(\alpha_{1}^{u}\right)^{2}
$$


The optimal price (and thus, market share) satisfies the first-order condition:

$$
v-c-\frac{3}{4}\left(\mu_{1}^{u}\right)^{2}+\frac{\alpha_{1}^{u} \mu_{1}^{u}}{16}=0,
$$

where we can verify that $\mu_{1}^{u}$ must be the positive root of Equation 25 to be positive. Combining Equations 23 and 25, firm 1's optimal price is given by

$$
p_{1}^{u}=c+\frac{1}{2}\left(\mu_{1}^{u}\right)^{2}-\frac{\alpha_{1}^{u} \mu_{1}^{u}}{32} .
$$

Thus, firm 1's profit $\left(\Pi_{1}^{u}\right)$ is given by

$$
\Pi_{1}^{u}=\left(p^{u}-c\right) \mu_{1}^{u}-c_{\alpha}\left(\alpha_{1}^{u}\right)^{2}=\left(\frac{1}{2}\left(\mu_{1}^{u}\right)^{2}-\frac{\alpha_{1}^{u} \mu_{1}^{u}}{32}\right) \mu_{1}^{u}-c_{\alpha}\left(\alpha_{1}^{u}\right)^{2} .
$$

Given that both firms' decisions are identical, there may exist an equilibrium in which firm 2 behaves identically: $p_{2}^{u}=p_{1}^{u}$ and $\alpha_{2}^{u}=\alpha_{1}^{u}$. Suppose that firm 1 were to deviate by choosing $\alpha_{1}^{\prime}>\alpha_{1}^{u}$ such that it earns market share $\mu_{1}^{\prime}>\mu_{1}^{u}$ and covers the market, while firm 2 maintains its market share (i.e. $\alpha_{1}^{\prime}$ such that $\mu_{1}^{\prime}=1-\mu_{2}^{u}$, where $\mu_{2}^{u}=\mu_{1}^{u}$ ). The profit from such a deviation $\left(\Pi_{1}^{\prime}\right)$ would be

$$
\Pi_{1}^{\prime}=\left(p_{1}^{\prime}-c\right) \mu_{1}^{u}-c_{\alpha}\left(\alpha_{1}^{\prime}\right)^{2}=\left(\frac{1}{4}+\frac{1}{48}\left(\alpha_{1}^{\prime}-\alpha_{2}^{u}\right)\right) \mu_{1}^{u}-c_{\alpha}\left(\alpha_{1}^{\prime}\right)^{2} .
$$

We know from our previous analysis that $\Pi_{1}^{\prime}>\Pi_{2}^{\prime}$, where $\Pi_{2}^{\prime}$ is firm 2's profit given $\alpha_{1}^{\prime}$ and $\alpha_{2}^{u}=\alpha_{1}^{u}$. But notice that $\alpha_{2}^{u}=\alpha_{1}^{u}$, so $\mu_{2}^{u}=\mu_{1}^{u}$. Comparing $\Pi_{2}^{\prime}$ to $\Pi_{1}^{u}$, note that $p_{2}^{\prime}=c+\frac{1}{4}+\frac{1}{96}\left(\alpha_{1}^{\prime}-\alpha_{2}^{u}\right)$ when the market is covered. In contrast, when the market is uncovered, firm 2 charges the price

$$
\begin{aligned}
p_{2}^{u} & =c+\frac{1}{2}\left(\mu_{2}^{u}\right)^{2}-\frac{\alpha_{1}^{u} \mu_{2}^{u}}{32} \\
& <c+\frac{1}{2}\left(\frac{1}{2}\right)^{2}-\frac{\alpha_{1}^{u} \mu_{2}^{u}}{32} \\
& <c+\frac{1}{8}-\frac{\alpha_{1}^{u} \mu_{2}^{u}}{32} \\
& \leq c+\frac{1}{8}<c+\frac{1}{4}<p_{2}^{\prime} .
\end{aligned}
$$

Thus, firm 2 earns greater profits $\left(\Pi_{2}^{\prime}>\Pi_{2}^{u}\right)$ when firm 1 deviates to the specified $\alpha_{1}^{\prime}$. But since $\Pi_{2}^{u}=\Pi_{1}^{u}$ and we have already shown that $\Pi_{1}^{\prime}>\Pi_{2}^{\prime}$, then $\Pi_{1}^{\prime}>\Pi_{1}^{u}$. This implies that when the covered market equilibrium exists, there is no symmetric equilibrium in which the market is uncovered such that $\mu_{1}=\mu_{2}<\frac{1}{2}$ and $\mu_{1}+\mu_{2}<1$.

Finally, suppose there is an equilibrium in which the market is uncovered and one firm 
(say, firm 2) covers over half the market $\left(\mu_{2}>\frac{1}{2}>\mu_{1}\right.$ and $\left.\mu_{2}+\mu_{1}<1\right)$. Then it must be that firm 1 sets price $p_{1}^{u}$, covers less than half the market $\left(\mu_{1}^{u}<\frac{1}{2}\right)$ and earns $\Pi_{1}^{u}$. Suppose that firm 1 deviates by choosing $\alpha_{1}^{\prime \prime}$ and $p_{1}^{\prime \prime}$ such that its subsequent market share satisfies $\mu_{1}^{\prime \prime}+\mu_{2}=1$, where firm 2's market share $\mu_{2}$ is unchanged by this deviation. It must be that $\mu_{1}^{\prime \prime}>\mu_{1}^{u}$. Moreover, we have already shown in the preceding proof that $p_{1}^{\prime \prime}>p_{1}^{u}$. Firm 1 can achieve this by selecting $\alpha_{1}^{\prime \prime}=0$ and selecting price $p_{1}^{\prime \prime}\left(\alpha_{1}^{\prime \prime}=0\right)$ so that $\mu_{1}^{\prime \prime}\left(\alpha_{1}^{\prime \prime}=0\right)+\mu_{2}=1$. Thus, firm 1 can profitably deviate by choosing $\left(\alpha_{1}^{\prime \prime}, p_{1}^{\prime \prime}\right)$ such that the market is covered. This implies that when the covered market equilibrium exists, there is no equilibrium in which the market is uncovered such that $\mu_{1}<\frac{1}{2}<\mu_{2}$ and $\mu_{1}+\mu_{2}<1$. Note that this argument also implies that in the covered equilibrium, the firm that does not invest in meeting technology has no incentive to deviate to a price and investment choice such that the market is no longer covered.

Thus, I have shown that when the covered market equilibrium exists, there is no equilibrium in which the market is uncovered such that $\mu_{1}+\mu_{2}<1$. The intuition for this result is that the non-monotonic relationship between market share and information benefits weakens price competition in the covered market sufficiently that both firms extract all consumers' information surplus through pricing and more. If the market is not covered, the firm with lower market share is unable to benefit from the larger firm's behavior and mark up its prices. For this reason, it has an incentive to change its investment and pricing strategies to cover the market.

The maximal price that can be charged in a covered market is attained when $\alpha_{1}=\bar{\alpha}_{1}$ (i.e., when $c_{\alpha} \leq \underline{c}_{\alpha}$ ). Thus, an equilibrium with a covered market certainly exists for any $c_{\alpha} \geq 0$ when the marginal consumer prefers to purchase rather than abstain, which occurs when $v-c \geq 0.32821$ :

$$
\begin{array}{r}
v-p^{E I}\left(\bar{\alpha}_{1}\right)-\left(\frac{1}{2} \mu_{1}^{E I}\left(\bar{\alpha}_{1}\right)\right)^{2}+\frac{\bar{\alpha}_{1}\left(1-\mu_{1}^{E I}\left(\bar{\alpha}_{1}\right)\right)}{32} \geq 0 \\
v-c \geq \frac{2275}{6144}-\frac{15}{2048} \sqrt{33} \approx 0.32821
\end{array}
$$




\section{References}

Alcalá, F., M. GonzÁlez-Maestre, And I. Martínez-Pardina (2006): "Competition versus Information under the Word-of-Mouth Effect," Working paper.

Alós-Ferrer, C. (1999): "Dynamic Systems with a Continuum of Randomly Matched Agents," Journal of Economic Theory, 86, 245-267.

Austen-Smith, D. And R. G. Fryer (2005): "An Economic Analysis of 'Acting White'," The Quarterly Journal of Economics, 120, 551-583.

Bagwell, L. S. And B. D. Bernheim (1996): "Veblen Effects in a Theory of Conspicuous Consumption," American Economic Review, 86, 349-73.

Bala, V. And S. Goyal (1998): "Learning from neighbours," Review of Economic Studies, 65, 595-621.

(2001): "Conformism and diversity under social learning," Economic Theory, 17, $101-120$.

Banerjee, A. And T. Besley (1990): "Peer Group Externalities And The Learning Incentives: A Theory Of Nerd Behavior," Papers 68, Princeton, Woodrow Wilson School - Discussion Paper, available at http://ideas.repec.org/p/fth/priwdp/68.html.

Battaglini, M., R. BÉnabou, And J. Tirole (2005): "Self-control in peer groups," Journal of Economic Theory, 123, 105-134.

Bergemann, D. And D. Ozmen (2004): "Optimal Pricing Policy with Recommender Systems," Available at http://citeseer.ist.psu.edu/bergemann04optimal.html.

Bernheim, B. D. (1994): "A Theory of Conformity," The Journal of Political Economy, $102,841-877$.

Bikhchandani, S., D. Hirshleifer, And I. Welch (1998): "Learning from the Behavior of Others: Conformity, Fads, and Informational Cascades," The Journal of Economic Perspectives, 12, 151-170.

Corneo, G. And O. Jeanne (1997): "Conspicuous consumption, snobbism and conformism," Journal of Public Economics, 66, 55 - 71.

(1999): "Segmented communication and fashionable behavior," Journal of Economic Behavior \& Organization, 39, 371 - 385. 
D'Aspremont, C., J. J. Gabszewicz, and J.-F. Thisse (1979): "On Hotelling's "Stability in Competition"," Econometrica, 47, pp. 1145-1150.

Dos Santos Ferreira, R. and J.-F. Thisse (1996): "Horizontal and vertical differentiation: The Launhardt model," International Journal of Industrial Organization, 14, 485 -506 .

ECONOMIDES, N. (1993): "Quality variations in the circular model of variety-differentiated products," Regional Science and Urban Economics, 23, 235-257.

Ellison, G. And D. Fudenberg (1995): "Word-of-Mouth Communication and Social Learning," The Quarterly Journal of Economics, 110, 93-125.

Feldman, M. And C. Gilles (1985): "An expository note on individual risk without aggregate uncertainty," Journal of Economic Theory, 35, 26-32.

Galeotti, A., S. Goyal, and J. Kamphorst (2006): "Network formation with heterogeneous players," Games and Economic Behavior, 54, 353-372.

Jackson, M. O. And A. Wolinsky (1996): "A Strategic Model of Social and Economic Networks," Journal of Economic Theory, 71, 44-74.

JUDD, K. L. (1985): "The law of large numbers with a continuum of IID random variables," Journal of Economic Theory, 35, 19-25.

Kats, A. (1995): "More on Hotelling's stability in competition," International Journal of Industrial Organization, 13, $89-93$.

Katz, M. L. And C. Shapiro (1985): "Network Externalities, Competition, and Compatibility," The American Economic Review, 75, pp. 424-440.

Kuksov, D. (2007): "Brand Value in Social Interaction," Management Science, 53, 16341644.

Kuksov, D. And Y. XIE (2010): "Pricing, Frills, and Customer Ratings," Marketing Science, 29, 925-943.

Laffont, J.-J., P. Rey, And J. Tirole (1997): "Network Competition: I. Overview and Nondiscriminatory Pricing," The RAND Journal of Economics, 29, pp. 1-37.

Muñiz, Jr., A. M. And T. C. O'Guinn (2001): "Brand Community," Journal of Consumer Research, 27, 349-73. 
NAVARro, N. (2006): "Asymmetric information, word-of-mouth, and social networks: from the market for lemons to efficiency," CORE Discussion Paper, 2006/02.

O'Guinn, T. C. And A. M. MuÑIz, JR. (2005): "Communal consumption and the brand," in Inside Consumption: Consumer motives, goals, and desires, ed. by S. Ratneshwar and D. G. Mick, Routledge, 252-272.

Pesendorfer, W. (1995): "Design Innovation and Fashion Cycles," The American Economic Review, 85, 771-792.

SAlop, S. C. (1979): "Monopolistic Competition with Outside Goods," The Bell Journal of Economics, 10, pp. 141-156.

Shaked, A. And J. Sutton (1982): "Relaxing Price Competition Through Product Differentiation," The Review of Economic Studies, 49, 3-13.

Vettas, N. (1997): "On the Informational Role of Quantities: Durable Goods and Consumers' Word- of-Mouth Communication," International Economic Review, 38, 915-944. 